\title{
The impact of PARPs and ADP-ribosylation on inflammation and host-pathogen interactions
}

\author{
Anthony R. Fehr, ${ }^{1}$ Sasha A. Singh, ${ }^{2}$ Catherine M. Kerr, ${ }^{1}$ Shin Mukai, $^{2}$ Hideyuki Higashi, ${ }^{2}$ \\ and Masanori Aikawa ${ }^{2,3,4}$ \\ ${ }^{1}$ Department of Molecular Biosciences, University of Kansas, Lawrence, Kansas 66045, USA; ${ }^{2}$ Center for Interdisciplinary \\ Cardiovascular Sciences, Cardiovascular Division, Brigham and Women's Hospital, Harvard Medical School, Boston, \\ Massachusetts 02115, USA; ${ }^{3}$ Center for Excellence in Vascular Biology, Brigham and Women's Hospital, Harvard Medical School, \\ Boston, Massachusetts 02115, USA; ${ }^{4}$ Department of Human Pathology, I.M. Sechenov First Moscow State Medical University of \\ the Ministry of Health, Moscow 119146, Russian Federation
}

Poly-adenosine diphosphate-ribose polymerases (PARPs) promote ADP-ribosylation, a highly conserved, fundamental posttranslational modification (PTM). PARP catalytic domains transfer the ADP-ribose moiety from $\mathrm{NAD}^{+}$ to amino acid residues of target proteins, leading to monoor poly-ADP-ribosylation (MARylation or PARylation). This PTM regulates various key biological and pathological processes. In this review, we focus on the roles of the PARP family members in inflammation and host-pathogen interactions. Here we give an overview the current understanding of the mechanisms by which PARPs promote or suppress proinflammatory activation of macrophages, and various roles PARPs play in virus infections. We also demonstrate how innovative technologies, such as proteomics and systems biology, help to advance this research field and describe unanswered questions.

Polyadenosine diphosphate-ribose polymerases (PARPs) promote ADP-ribosylation, one of the fundamental posttranslational modifications (PTMs) (Gupte et al. 2017). This ubiquitous PTM regulates various key biological and pathological processes, including DNA repair, cell differentiation, gene transcription, signal transduction pathways, energy metabolism, and epigenetics. PARP catalytic domains transfer the ADP-ribose moiety from $\mathrm{NAD}^{+}$to amino acid residues of target proteins, leading to monoor poly-ADP-ribosylation (MARylation or PARylation). PARP members thus function as "writers" of ADP-ribose. Among the 17 human PARPs, PARP1, PARP2, PARP5A,

[Keywords: ADP-ribosylation; PARP; atherosclerosis; host-pathogen interactions; immunity; inflammation; macrophage; vascular disease] Corresponding authors: maikawa@bwh.harvard.edu, arfehr@ku.edu Article published online ahead of print. Article and publication date are online at http://www.genesdev.org/cgi/doi/10.1101/gad.334425.119. Freely available online through the Genes \& Development Open Access option. and PARP5B promote PARylation, while most other members (e.g., PARP3, PARP4, PARP6, PARP14, and PARP15) catalyze MARylation (Hottiger 2015; Ryu et al. 2015; Gupte et al. 2017). A new nomenclature has thus been proposed to call them the diphtheria toxin-like ADP-ribosyltransferases (ARTDs); e.g., ARTD1 for PARP1 (Hottiger et al. 2010). Differences between each PARP lead to diverse functions for PARPs in biological processes such as the innate immune response (Fig. 1).

PARP family members contain a few structural domains, in addition to the catalytic domain. One of such domains is the macrodomain that is contained in PARP9, PARP14, and PARP15, for which they are called "macro" PARPs. Macrodomains bind to, and in some cases hydrolyze, ADP-ribose in the free or protein-bound form ("readers" of ADP-ribosylation) and influence many biological processes (Rack et al. 2016). Evidence has linked the MacroPARPs PARP9 and PARP14 in multiple types of cancers, particularly lymphomas (Aguiar et al. 2000; Cho et al. 2009). PARP14 may also play an important role in cell morphology (Vyas et al. 2013). We found the interplay of PARP9 and PARP14 in the regulation of macrophage activation (Iwata et al. 2016), as described in this review.

Different cellular distributions of PARPs may also indicate their distinctive targets and functions (Vyas et al. 2013). While PARP1 is only found in the nucleus, PARP6, PARP8, PARP12, PARP13, PARP15, and PARP16 are mostly located in the cytoplasm. PARP2, PARP3, PARP4, PARP5A, PARP5B, PARP7, PARP9, PARP10, PARP11, and PARP14 are seen in both the nucleus and cytoplasm.

ADP-ribolylation is reversed by "erasers" such as polyADP-ribose glycohydrolase (PARG), ADP-ribosylhydrolase 3 (ARH3), and macrodomains such as Mdo2 (Miwa and Sugimura 1971; Oka et al. 2006; Jankevicius et al.

(c) 2020 Fehr et al. This article, published in Genes \& Development, is available under a Creative Commons License (Attribution 4.0 International), as described at http://creativecommons.org/licenses/by/4.0/. 
Fehr et al.
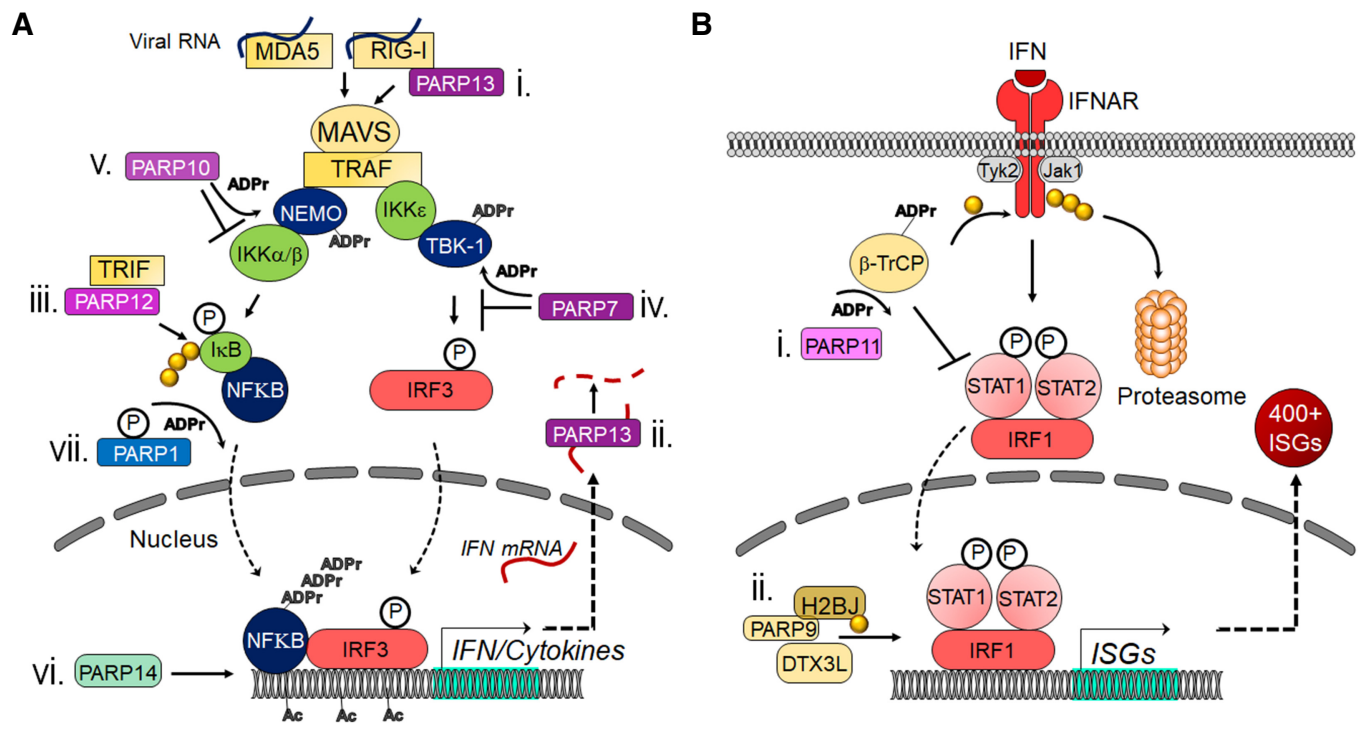

Figure 1. PARPs regulate the innate immune response at many different points. $(A)$ Mechanisms used by MARylating and nonenzymatic PARPs to modulate IFN and proinflammatory cytokine induction. (i) PARP13 can bind to RIG-I, which promotes its oligomerization and the initiation of the cascade. (ii) PARP13 can also bind to IFN mRNA and target it for degradation. (iii) PARP12 was shown to bind TRIF and enhance NFkB-dependent gene expression. (iv) PARP7 can ADP-ribosylate TBK-1, which inhibits it from phosphorylating IRF3. (v) PARP10 can interact with and ADP-ribosylate NEMO, which prevents the activation of IKKs. (vi) PARP14 promotes H3K27 acetylation and recruitment of Pol II to IFN promoters. (vii) Upon phosphorylation, PARP1 can poly-ADP-ribosylate NFkB and promote its activity. (B) Mechanisms used by MARylating and nonenzymatic PARPs to modulate IFN-I signaling. (i) PARP11 binds to and ADP-ribosylates the E3 ubiquitin ligase $\beta$-TrCP. This allows $\beta$-TrCP to interact with and ubiquitinate IFNAR, which targets it for proteasome-dependent degradation. (ii) PARP9 and DTX3L interact with and ubiquitinate histone protein $\mathrm{H} 2 \mathrm{BJ}$, which leads to chromatin remodeling that enhances expression of a subset of ISGs. (P) Phosphate group; (ADPr) ADP-ribose; (Ac) acetyl modification; (yellow ciricle) ubiquitin.

2013; Rosenthal et al. 2013). PARG is a potent enzyme that degrades poly-ADP-ribose, with several isoforms that are derived from the single PARG gene through alternative splicing (i.e., 110-, 102-, 99-, and 60-kDa proteins). The $110-\mathrm{kDa}$ isoform, mostly seen in the nucleus, appears to play a dominant role in the PAR degradation. PARG cannot erase ADP-ribose when bound to proteins and leaves MARylated amino acid residues. PARG is a useful tool that enables researchers the ability to enrich for MARylated peptides for mass spectrometry analysis of ADP-ribosylation (Higashi et al. 2019).

\section{PARPS in immune cells: a focus on inflammation}

Immune cells serve an important role in the immune system and differentiate into various subsets that perform a spectrum of unique functions. The balance of the number of different immune cell types and their activation levels is crucial for health and disease. Overwhelming evidence has associated chronic inflammation with various pathological conditions and their potential causes, including atherosclerosis, cardiovascular events, cancer, autoimmune diseases, metabolic disorders, neurological diseases, and aging (Johnston et al. 1987; Gisterå and Hansson 2017; Tabas and Lichtman 2017; de Vries and Quax 2018; Gomez et al. 2018; Aday and Ridker 2019; Bercovici et al. 2019; Di Benedetto et al. 2019; Guner and Kim 2019; Horwitz et al. 2019; O'Rourke et al. 2019; Othman et al.
2019; Trott and Fadel 2019). Many investigations have focused on the major role of macrophages in such contexts and mechanisms for their proinflammatory activation (Murray and Wynn 2011; Wynn and Vannella 2016; Gisterå and Hansson 2017; Tabas and Lichtman 2017; Decano and Aikawa 2018; Funes et al. 2018; Swirski and Nahrendorf 2018; O'Rourke et al. 2019). Various signal-transduction pathways participate in macrophage activation, which are often regulated by PTMs such as phosphorylation and acetylation (Tietzel and Mosser 2002; Park et al. 2011; Zhou et al. 2014; Nakano et al. 2016; Vergadi et al. 2017; Dean et al. 2019). This section focuses on the impact of PARPs and ADP-ribosylation in macrophage activation and also summarizes their roles in the biology of other immune cells.

\section{PARP1 induces macrophage activation and inflammation}

Evidence suggests that ADP-ribosylation participates in inflammation (Bai and Virág 2012; Rosado et al. 2013; Kunze and Hottiger 2019). PARP1 has been implicated in the mechanisms for responses (e.g., proinflammatory cytokine expression) of macrophages or macrophage-like cell lines to pathogen-associated molecular patterns (PAMPs), including lipopolysaccharide (LPS) (Hassa et al. 2005; Liu et al. 2012a; Yang et al. 2014; Minotti et al. 2015; Bohio et al. 2019). Some responses involve the interplay between PARP1 and nuclear factor $\kappa \mathrm{B}(\mathrm{NF}-\kappa \mathrm{B})$, a key 
transcription factor in immunity and various other biological processes (Hassa and Hottiger 1999; Hassa et al. 2005; Liu et al. 2012a; Minotti et al. 2015; Bohio et al. 2019; Kunze and Hottiger 2019). Using PARP1-deficient mice Oliver et al. (1999) provided evidence that PARP1 promotes NF- $\mathrm{KB}$ activation in macrophages in vivo. This study demonstrated that Parp1 deletion causes resistance to LPS-induced endotoxic shock by NF- $\kappa B$-dependent iNOS induction and NO production. Recent evidence suggests that phosphorylation of PARP1 results in PARylation of the NF- $\mathrm{BB}$ subunit p65/RelA, which induces the transcription of NF-kB-regulated genes (Fig. 1A; Bohio et al. 2019). PARP1 also induces the release of the high-mobility group box 1 (HMGB1), a proinflammatory factor, from the nucleus to the cytoplasm in macrophages, which requires its PARylation and subsequent acetylation (Ditsworth et al. 2007; Yang et al. 2014). PARP1 also exerts proinflammatory effects on other macrophage-related cell types such as Kupffer cells in the fatty liver and microglia in the injured brain (Ullrich et al. 2001; Mukhopadhyay et al. 2017). In some cases, PARP-1-induced activation of proinflammatory mediators, such as NF- $\kappa \mathrm{B}$, do not depend on its enzymatic activity, suggesting mechanisms used by PARP1 to impact inflammation depend on the context or its targets (Hassa et al. 2005; Minotti et al. 2015).

\section{The role of nicotinamide adenine dinucleotide $\left(N A D^{ \pm}\right)$ in PARP1-mediated macrophage activation}

PARPs catalyze the transfer of ADP-ribose from $\mathrm{NAD}^{ \pm}$to target proteins. Hence, $\mathrm{NAD}^{ \pm}$is consumed by PARPs, and the activity of PARPs depends on the availability of $\mathrm{NAD}^{ \pm}$ (Gupte et al. 2017). A recent report indicates that cellautonomous production of $\mathrm{NAD}^{ \pm}$via the kynurenine pathway $(\mathrm{KP})$ is required to induce normal inflammatory macrophage activation and that the de novo $\mathrm{NAD}^{ \pm}$synthesis can be impaired in aged macrophages (Minhas et al. 2019). Another study proposed a mechanism linking the $\mathrm{NAD}^{ \pm}$salvage pathway to LPS-induced PARP1 consumption of $\mathrm{NAD}^{ \pm}$(Cameron et al. 2019). In LPS-stimulated macrophages, an increase in reactive oxygen species induces DNA damage, which in turn activates

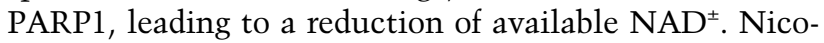
tinamide phosphoribosyltransferase (NAMPT) is therefore increased to maintain $\mathrm{NAD}^{ \pm}$levels, which is crucial for normal inflammatory macrophage activation.

\section{PARP1 participates in the biology of other immune cells}

PARP1 modulates the differentiation of T cells into effector $\mathrm{T}$ cells such as $\mathrm{T}$ helper 1 (Th1), $\mathrm{T}$ helper 2 (Th2), and regulatory $\mathrm{T}$ cells (Tregs) (Saenz et al. 2008; Nasta et al. 2010). PARP1 deficiency in murine $T$ cells leads to the increased expression of the Th1 cytokine interferon- $\gamma$ $($ IFN- $\gamma$ ) and the decreased production of the Th2 cytokine interleukin 4 (IL-4) (Saenz et al. 2008). IL-4 suppresses IFN $\gamma$ secretion and Th1 differentiation, and PARP1 promotes IL-4 expression via chromatin modifications at the IL-4 locus (Saenz et al. 2008). Although PARP1 is not involved in the differentiation of naïve $\mathrm{T}$ cells into $\mathrm{T}$ helper 17 (Th17) cells, it does impact Tregs, as these cells are augmented in multiple organs in PARP1-deficient mice (Nasta et al. 2010). Using PARP1-deficient mice, Nasta et al. (2010) demonstrated that PARP1 supresses the expression of Foxp3 and thus generation of Tregs via modulation of the chromatin structure and/or regulation of the transcription factors. Additional studies used PARP1-deficiet mice further demonstrated mechanisms for PARP1-regulated suppression of Tregs via transforming growth factor $\beta$ (TGF $\beta$ ) receptors (Zhang et al. 2013). Recent reports demonstrate the interactive role of PARP1 and PARP2 in maintaining the number and function of $\mathrm{T}$ cells and promoting the development and function of B cells (Navarro et al. 2017; Galindo-Campos et al. 2019). Defective thymocyte maturation is observed in PARP1/PARP2-deficient mice, and accordingly T-cell numbers in peripheral blood are reduced (Galindo-Campos et al. 2019). In PARP1/PARP2-deficient mice, the development of bone marrow B cells is impaired, leading to the reduction of transitional and follicular B cells (Navarro et al. 2017). PARP1 also plays a role in the maturation and function of dendritic cells by regulating the production of IL-10 and IL-12 (Aldinucci et al. 2007).

\section{PARP1 promotes experimental cardiovascular disorders}

A series of in vivo studies from the Boulares and Matter groups (Oumouna-Benachour et al. 2007; von Lukowicz et al. 2008; Hans et al. 2009, 2011) used PARP1-deficient mice to demonstrate that PARP1 promotes the development of various cardiovascular disorders. Two studies reported that PARP1 deficiency in apolipoprotein E-deficient $\left(A p o E^{-/-}\right)$mice reduces the size, macrophage and T-cell content, death of macrophage foam cells, necrotic core, NF-kB activation, and adhesion molecule expression in experimental atherosclerotic lesions, typical features of human plaques prone to acute thrombotic events (Oumouna-Benachour et al. 2007; von Lukowicz et al. 2008). Parp1 deletion attenuates dyslipidemia-induced vascular dysfunction in $A p o E^{-/-}$mice seemingly via maintenance of eNOS activity (Hans et al. 2011). PARP1 deficiency furthermore improves delated cardiomyophathy and concomitantly increases tissue inhibitor of metalloproteinase 2 (TIMP2) in $A p o E^{-/-}$mice (Hans et al. 2009).

\section{PARP9 and PARP14 regulate macrophage activation}

While many reports suggested multiple proinflammatory roles for PARP1, contributions of other PARP family members in macrophage activation remain incompletely understood. We demonstrated that PARP9 and PARP14 coregulate proinflammatory activation of human macrophages (Iwata et al. 2016). In this study we took a systems-biology approach involving unbiased proteomics, bioinformatics, and network analysis to identify potential molecular switches of the balance of proinflammatory versus non/anti-inflammatory macrophage phenotypes as potential therapeutic targets. We performed proteomics of human and mouse macrophage-like cell lines 
treated with IFN $\gamma$ or IL-4, which represent so-called proinflammatory M1 versus non/anti-inflammatory M2 cells. We processed our proteomics data of $>5000$ proteins with a conventional filtering method as well as our original clustering method (Ricchiuto et al. 2015) to identify molecules that increased with IFN $\gamma$ and decreased with IL-4 (Iwata et al. 2016). Interestingly, the only protein that emerged from this stringent criteria was PARP14. We also recognized that PARP9 showed similar responses.

The same study demonstrated in vitro that PARP14 suppresses proinflammatory IFN $\gamma-\mathrm{STAT} 1$ signaling and activates the anti-inflammatory IL-4-STAT6 pathway in primary human macrophages (Fig. 2; Iwata et al. 2016). Silencing of PARP14 by siRNA accelerated the induction of proinflammatory cytokines and chemokines (e.g., TNFa, IL- $1 \beta$, and CCL2/MCP-1) in IFN $\gamma$-treated macrophages and suppressed anti-inflammatory molecules (e.g., MRCland Arg1) in IL-4-treated cells. PARP9 silencing generally exerted opposing effects. PARP9 also appeared to interfere with PARP14's suppressive action on the IFN $\gamma$-STAT1 axis, thus promoting proinflammatory macrophage activation (Fig. 2). Cell-free enzyme reactions with mass spectrometry as a read-out further indicated that ADP-ribosylation of STAT1 by PARP14 may reduce phosphorylation of this proinflammatory mediator. However, the mechanisms used by PARP14 to interact with STAT1 and influences its ADP-ribosylation and phosphorylation requires further investigations.

Due to the well-recognized knowledge that targets identified in basic science often fail in the clinical stage, we performed network analysis that closely linked the network of PARP9, PARP14, and their first neighbor interactors with the human coronary artery disease gene module (Fig. 3). As predicted, in vivo studies in Parp $14^{-/-}$mice demonstrated that PARP14 participates in the pathogenesis of arterial diseases. Consistent with in vitro studies, PARP14 deficiency indeed mitigated lesion development and inflammatory burden in models of coronary artery disease in mice (Iwata et al. 2016).

The anti-inflammatory role of PARP14 reported by us are consistent with other reports. Iqbal et al. (2014) demonstrated in macrophages that PARP14 reduces mRNA stability and thus expression levels of tissue factor, a surface glycoprotein that plays a major thrombogenic role in macrophage-rich atherosclerotic lesions. PARP14's association with anti-flammatory STAT6 was first described using a yeast two-hybrid screen (Goenka and Boothby 2006). Although subsequent studies were not done in the context of macrophage activation, they indicated that PARP14's enhancement of IL-4 STAT6's transcriptional activity may be more relevant to its promoter binding functions rather than its potential to ADP-ribosylate STAT6 itself (Fig. 2; Goenka et al. 2007; Mehrotra et al. 2011). For instance, PARP14 can act as a transcriptional repressor of STAT6 target genes, but activation by IL-4 leads to its autoribosylation and dissociation of PARP14 from a DNA-protein complex, thereby promoting STAT6 binding instead (Fig. 2; Goenka et al. 2007; Mehrotra et al. 2011). Thus, despite the accumulating evidence that PARP14 promotes an anti-inflammatory state, there does not yet exist enough information to disentangle PARP14's enzymatic functions from that of its protein-interaction functions, and how each of these functions may maintain an anti-inflammatory response, irrespective of the cytokine or stimulus.

Evidence established that macrophages are a heterogeneous group of cells, as represented by the well-known theory of M1 versus M2 polarization. Recent understanding, however, suggests that macrophage heterogeneity is more complex and multidimensional than the M1/M2 dichotomy (Murray et al. 2014; Nahrendorf and Swirski 2016; Decano and Aikawa 2018). In our study, single-cell analysis demonstrated that IFN $\gamma$-elicited macrophages remain largely heterogeneous, consisting of a few clusters rather than uniformly "polarized" toward an activated phenotype (Iwata et al. 2016). Gene similarity maps demonstrated close interactions between PARP9, PARP14, STAT1, and STAT6, supporting our in vitro data described above.

\section{PARP14 regulates lymphocyte biology}

Several pieces of evidence demonstrate that PARP14 promotes the differentiation of naïve T cells into Th2 cells by

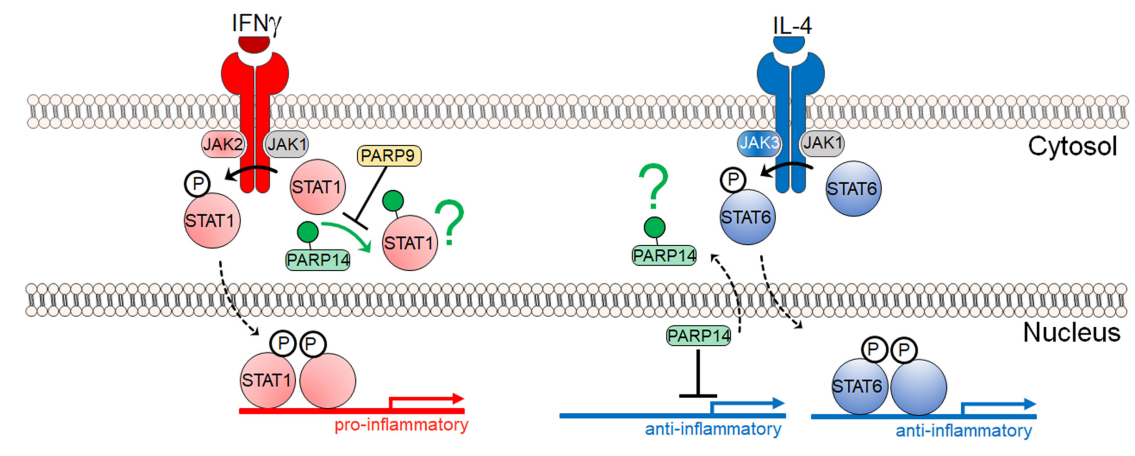

promoter(s), thereby allowing phosphorylated STAT6 to bind and activate target genes (Mehrotra et al. 2011). A gree question mark inpromoter(s), thereby allowing phosphorylated STAT6 to bind and activate target genes (Mehrotra et al. 2011). A green question mark in-
dicates that the fate of ADP-ribosylated substrates is not known. The IFN $\gamma$ and IL-4 mechanisms appear distinct, but they may be partial and complementary pictures of a complex biology.

Figure 2. A partial model of PARP14 and PARP9 function in macrophage activation. In vivo and in vitro studies pertaining to IFNg signaling in primarily macrophages suggest that PARP14 mitigates proinflammatory phosphorylated STAT1 via ADP-ribosylation, and that PARP9 may act to inhibit PARP14's enzymatic activity (Iwata et al. 2016). In vitro studies pertaining to IL-4 signaling in the context of B-cell biology suggest that in nonstimulating conditions PARP14 is a suppressor of STAT6 target genes. In response to IL-4, PARP14 is thought to become enzymatically active and dissociate from the 


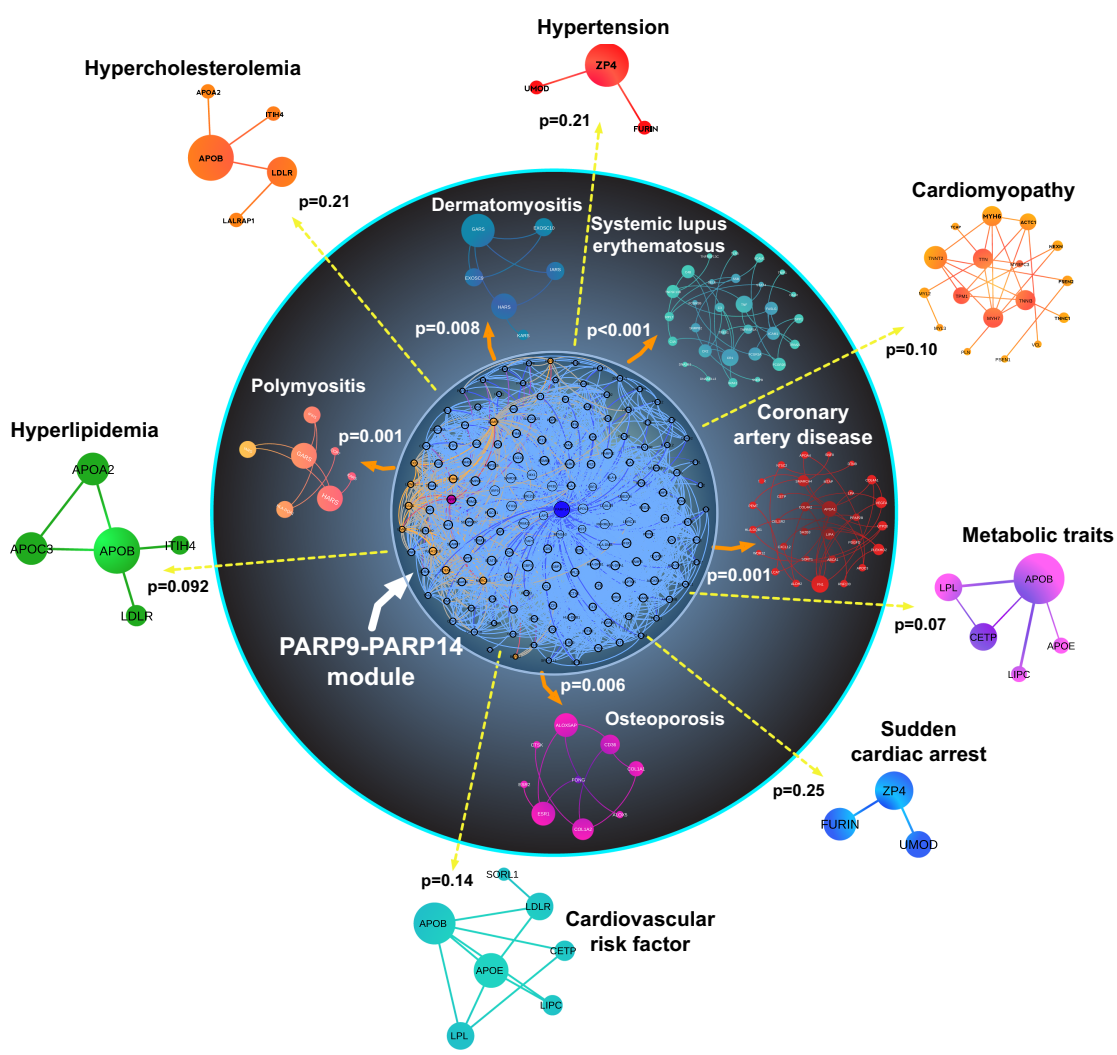

Figure 3. Computational prediction of an association between the PARP9-PARP14 network and human inflammatory diseases. The network of PARP14 (blue)-PARP9 (purple) consists of proteins that directly interact with these PARPs (blue and orange nodes, respectively). $P$-values indicate the significance of closeness between the PARP14-PARP9 first neighbors in the interactome (the PARP9-PARP14 module) and gene modules of human diseases such as coronary artery disease compared with random expectation. Reproduced from Iwata et al. (2016). regulating STAT6-dependent Gata3 expression and that PARP14-deficient mice show reduced symptoms of allergic airway disease (Mehrotra et al. 2013; Riley et al. 2013). PARP14 enhances STAT3-dependent Th17 differentiation (Mehrotra et al. 2015). PARP14 is also implicated in immunoglobulin class switching in B cells by enhancing the IL-4 and STAT6 signal, which produces the IgE isotype, a major factor in allergic hypersensitivity (Mehrotra et al. 2011).

\section{Other PARPs in macrophage biology}

As discussed, while several studies have reported how PARP1, PARP2, PARP9, and PARP14 promote or suppress macrophage activation via signaling pathways (e.g. NF- $\kappa \mathrm{B}$, IFN $\gamma$-STAT1, and IL-4-STAT6), the evidence remains scant on the roles that other PARPs play in macrophage biology. LPS increases the mRNA expression of PARP3, PARP4, PARP7, PARP8, PARP10, PARP11, PARP12, and PARP13 in murine bone marrow-derived macrophages, but there are no known functions for these PARPs in macrophage biology (Caprara et al. 2018). Other reports have linked PARP10 and PARP12 with NF-kB signaling (Verheugd et al. 2013; Welsby et al. 2014). Although these lines of evidence may suggest roles of PARPs other than PARP1, PARP2, PARP9, and PARP14 in macrophage biology, more investigations are needed to better understand how these PARPs participate in macrophage activation and inflammatory diseases.

\section{$P A R P s$ in cancer immunology}

PARPs have been targets for drug development, particularly in the cancer field. The most active targets include PARP1, and more recently PARP14 (Berger et al. 2018; Qin et al. 2019). Studies that used the small molecule inhibitors demonstrated that PARP suppression reduces proinflammatory responses or enhances anti-inflammatory functions of macrophages (Haskó et al. 2002; Wang et al. 2013; Shrestha et al. 2016; Dharwal et al. 2019). Recent work showed that PARP inhibition in combination with PD-1/PD-L1 blockade could be effective for BRCA1-deficient tumors by activating antigen presenting cells such as dendritic cells via the cGAS-STING pathway (Jiao et al. 2017; Ding et al. 2018; Dunphy et al. 2018). Major effects reported in these studies may reflect PARP1 suppression. These inhibitors, however, are not strictly specific for PARP1 and their effects on other PARP members and targets other than PARPs thus need to be addressed (Wahlberg et al. 2012).

\section{Activated macrophages link ADP-ribosylation with protein homeostasis}

A global view of PARP activity on immunity undoubtedly requires proteomics. However, even with the most advanced mass spectrometry technologies available, disentangling the unique and overlapping functions of PARPs remains very challenging. Only a handful of 
studies have begun to interrogate the complex biology of the PARP family members in the context of immunity.

Nearly 30 years ago, radioactive labeling strategies demonstrated an increase in ADP-ribosylation signal in human monocyte-derived macrophages in response to IFN $\gamma$ (Berton et al. 1991). In addition, there was no increase in PARP1 mRNA, implicating additional mechanisms rather than an increase in total PARP1 levels for the increase in ADP-ribosylation. Using quantitative proteomics, we made a similar observation in IFN $\gamma$-treated THP-1 and RAW264.7 macrophage-like cell lines (Iwata et al. 2016). Moreover, PARP14 and PARP9 exhibited the increased expression following IFN $\gamma$ exposure and had the opposite response to IL-4, decreasing in abundance over the stimulation period. These contrasting proinflammatory and anti-inflammatory responses by PARP9 and PARP14 were distinct from the other PARPs measured in the study. More specifically, their responses to IFN $\gamma$ were characteristic of known cytokine inducible genes, STAT1, NMI (Nmyc interactor), OAS2, IFIH1, and IFIT3, among several others. This study thus provided a plausible scenario where the increase in global ADP-ribosylation in macrophages could be mediated in part by PARP14 (Iwata et al. 2016).

In a separate study, using quantitative proteomics in combination with shRNA-mediated knockdown experiments, PARP14 interactors were pursued in the context of LPS signaling in RAW264.7 cells (Caprara et al. 2018). A PARP14 coimmunoprecipitation of these RAW264.7 cells after LPS treatment found that SQSTM1 (Sequestome-1, a receptor linking autophagy and ubiquitylation), PARP9, DTX3L, and NMI were immunoprecipitated with a PARP14 antibody specifically in PARP14 wild-type but not PARP14 knockdown cells, indicating that these proteins form a PARP14-protein interaction network in response to LPS.

Protein-protein interactions alone do not clarify the role of PARP enzyme activities in immunity. To date, only one study has investigated ADP-ribosylated substrates in immune cells on a global level (Higashi et al. 2019). Since ADP-ribosylome studies are technically challenging to perform; they rely on specialized proteomic workflows to enrich and sequence ADP-riboyslated peptides (Martello et al. 2016; Larsen et al. 2017). We used two independent approaches to enrich the ADPribosylome of IFN- $\gamma$-treated THP-1 cells. One approach used an anti-PARylation antibody enrichment that provided candidate ADP-ribosylated proteins, and the other enriched for MARylated peptides via their affinity for a macrodomain to identify ADP-ribosylated proteins (Higashi et al. 2019). The majority of proteins identified from both approaches combined, comprised ribosome/RNAbinding proteins. These findings were not surprising since this protein class is highly abundant, and thereby more conducive to identifying ADP-ribosylated peptides. Other ADP-ribosylated proteins were associated with pathways involved in neutrophil degranulation and activation, IL-12 signaling, and glycolysis. Moreover, ADPribosylation of a subset of the ribosome/RNA-binding proteins increased in response to IFN $\gamma$, as did ADP-ribo- sylated forms of PARP14 and PARP9, and interestingly SQSTM1, the ubiquitin pathway associated protein identified as a candidate PARP14 binding partner (Caprara et al. 2018). These studies point toward ADP-ribosylation linking macrophage activation with protein homeostasis, as indicated by the changes in ADP-ribosylation in numerous translational machinery; and by the emergence of proteins involved in ubiquitination (Higashi et al. 2019).

\section{PARPS, ADP-ribosylation, and host-pathogen interactions}

ADP-ribosylation is well-known to play an important role in many host-pathogen interactions. For instance, many important bacterial toxins are ADP-ribosyltransferases (ARTs). Bacterial pathogens such as B. pertussis, V. cholera, $P$. aeruginosa, C. botulinum, $S$. aureus, and $E$. coli encode for ARTs that target proteins such as elongation factor 2, actin, and Rho GTPases that lead to cell death (Holbourn et al. 2006). As discussed above, mammals also encode for a diverse set of ARTs, most of which are termed PARPs, that impact infections. Here we discuss mammalian encoded PARPs that are involved in hostpathogen interactions, focusing on virus infections.

\section{Mammalian PARPs display several properties indicative of involvement in host-pathogen interactions}

PARPs interact with pathogens in many ways, and here we describe specific cases where they either promote or restrict virus replication and the innate immune response. This discussion is summarized in Table 1 and Figure 1. However, we start by discussing characteristics that indicate an important role for PARPs in the host response to infection.

First, many mammalian PARPs are stimulated by the production of IFN (IFN-stimulated genes [ISGs]), and thus are part of the mammalian antiviral defense system (Atasheva et al. 2012; Zhang et al. 2015; Eckei et al. 2017; Li et al. 2018; Grunewald et al. 2019a). Also, several mono-ADP-ribosylating PARPs are rapidly evolving, indicating ongoing conflict with pathogens. The PARP domain of PARP13, a disordered region of PARP4, and the macrodomain(s) of the three macro-PARPs, PARP9, PARP14, and PARP15, are all under positive selection (Kerns et al. 2008; Daugherty et al. 2014). Furthermore, Parp14 and Parp15 have undergone multiple rounds of gene loss and duplication, which creates novel gene products needed for continual adaptation to new pathogens.

Several PARP proteins are also present in stress granules, which are important membrane-less organelles that function to restrict the translation of RNA when cells are under stress, such as during a virus infection. They are often characterized by the presence of TIA1, TIAR, and G3BP1, but are known to contain several hundred proteins (McCormick and Khaperskyy 2017). Interestingly, several proteins in stress granules are ADP-ribosylated, and PARPs, including 5a, 12, 13, 14, and 15, are known 
Table 1. PARPS with antiviral or proviral functions

\begin{tabular}{|c|c|c|c|c|c|}
\hline PARP/ARTH & $\begin{array}{l}\text { Mono or } \\
\text { poly }\end{array}$ & $\begin{array}{l}\text { Virus } \\
\text { targeted }\end{array}$ & $\begin{array}{l}\text { Proviral or } \\
\text { antiviral }\end{array}$ & Mechanisms & References \\
\hline PARP1/ARTD1 & Poly & $\begin{array}{l}\text { HIV-1 } \\
\text { MLV } \\
\text { MPSV } \\
\text { EBV } \\
\text { KSHV } \\
\gamma-2 \text { HV } \\
\text { PRRSV }\end{array}$ & $\begin{array}{l}\text { Both } \\
\text { Both } \\
\text { Pro } \\
\text { Anti } \\
\text { Anti } \\
\text { Anti } \\
\text { Pro }\end{array}$ & $\begin{array}{l}\text { Binds to TAR element to block HIV } \\
\text { transcription; binds to TR sequences } \\
\text { in KSHV; ADP-ribosylates EBNA1 to } \\
\text { prevent OriP from binding genome; } \\
\text { binds to and modified RTA protein of } \\
\gamma \text {-HVs to block transcription; binds to } \\
\text { PRRSV nucleocapsid protein }\end{array}$ & $\begin{array}{l}\text { Gäken et al. 1996; Kameoka et al. } \\
\text { 1999, 2004, 2005; Baekelandt } \\
\text { et al. 2000; Ha et al. 2001; } \\
\text { Gwack et al. 2003; Ariumi et al. } \\
\text { 2005; Parent et al. 2005; } \\
\text { Tempera et al. 2010; Grady } \\
\text { et al. 2012; Liu et al. 2012a; } \\
\text { Bueno et al. 2013; Chung et al. } \\
\text { 2015 }\end{array}$ \\
\hline PARP5a/ARTD5 & Poly & $\begin{array}{l}\text { HSV-1 } \\
\text { EBV }\end{array}$ & $\begin{array}{l}\text { Pro } \\
\text { Anti }\end{array}$ & $\begin{array}{l}\text { ADP-ribosylates EBNA1 to prevent OriP } \\
\text { from binding genome }\end{array}$ & $\begin{array}{l}\text { Deng et al. 2005; Grady et al. } \\
2012\end{array}$ \\
\hline PARP7/ARTD14 & Mono & $\begin{array}{l}\text { IAV } \\
\text { SINV } \\
\text { VEEV } \\
\text { RV } \\
\text { MHV }\end{array}$ & $\begin{array}{l}\text { Pro } \\
\text { Anti } \\
\text { Anti } \\
\text { Anti } \\
\text { Pro }\end{array}$ & $\begin{array}{l}\text { ADP-ribosylates TBK-1, which inhibits } \\
\text { IFN production; blocks cellular } \\
\text { translation; binds to viral RNA and } \\
\text { recruits exosomes to sites of } \\
\text { replication }\end{array}$ & $\begin{array}{l}\text { Atasheva et al. 2012, 2014; } \\
\text { Kozaki et al. 2017; Yamada } \\
\text { et al. 2016; Grunewald et al. } \\
\text { 2019b }\end{array}$ \\
\hline PARP12/ARTD12 & Mono & $\begin{array}{l}\text { VEEV } \\
\text { SINV } \\
\text { EMCV } \\
\text { VSV } \\
\text { CHIKV } \\
\text { ZIKA } \\
\text { MHV }\end{array}$ & $\begin{array}{l}\text { Anti } \\
\text { Anti } \\
\text { Anti } \\
\text { Anti } \\
\text { Anti } \\
\text { Anti } \\
\text { Anti }\end{array}$ & $\begin{array}{l}\text { Binds viral RNA and blocks translation; } \\
\text { targets Zika virus proteins for ADP- } \\
\text { ribosylation and degradation }\end{array}$ & $\begin{array}{l}\text { Atasheva et al. 2012, 2014; Li } \\
\text { et al. 2012; Liu et al. 2012b; } \\
\text { Grunewald et al. 2019a }\end{array}$ \\
\hline PARP13/ARTD13 & Inactive & $\begin{array}{l}\text { MLV } \\
\text { ALV-J } \\
\text { HIV-1 } \\
\text { SINV } \\
\text { SFV } \\
\text { RRV } \\
\text { PRRSV } \\
\text { EBOV } \\
\text { MARV } \\
\text { EV-A71 } \\
\gamma H V-68 \\
\text { HBV } \\
\text { IAV }\end{array}$ & $\begin{array}{l}\text { Anti } \\
\text { Anti } \\
\text { Anti } \\
\text { Anti } \\
\text { Anti } \\
\text { Anti } \\
\text { Anti } \\
\text { Anti } \\
\text { Anti } \\
\text { Anti } \\
\text { Anti } \\
\text { Anti } \\
\text { Anti }\end{array}$ & $\begin{array}{l}\text { Binds RNA leading to RNA degradation } \\
\text { or translation inhibition; targets } \\
\text { influenza proteins PB2 and PA for } \\
\text { ADP-ribosylation and degradation; } \\
\text { binds to RIG-I and promotes its } \\
\text { oligomerization; ZnF domains bind to } \\
\text { PRRSV nsp9 }\end{array}$ & $\begin{array}{l}\text { Gao et al. 2002; Bick et al. 2003; } \\
\text { Guo et al. 2007, 2019; Muller } \\
\text { et al. 2007; Hayakawa et al. } \\
\text { 2011; Zhu et al. 2011; Li et al. } \\
\text { 2015, 2017; Liu et al. 2015a; } \\
\text { Xuan et al. 2012, 2013; Mao } \\
\text { et al. 2013; Xie et al. 2018; } \\
\text { Zhao et al. 2019; Takata et al. } \\
2017\end{array}$ \\
\hline PARP9/ARTD9 & Mono $^{\mathrm{a}}$ & $\begin{array}{l}\text { EMCV } \\
\text { IAV } \\
\text { SINV }\end{array}$ & $\begin{array}{l}\text { Anti } \\
\text { Anti } \\
\text { Anti }\end{array}$ & $\begin{array}{l}\text { With DTX3L, ubiquitinates histone } \\
\text { H2BJ and enhances ISG expression }\end{array}$ & Zhang et al. 2015 \\
\hline PARP14/ARTD8 & Mono & MHV & Anti & $\begin{array}{l}\text { Enhances histone acetylation to } \\
\text { promote transcription of IFN-I genes }\end{array}$ & $\begin{array}{l}\text { Caprara et al. 2018; Grunewald } \\
\text { et al. 2019a }\end{array}$ \\
\hline PARP10/ARTD10 & Mono & VEEV & Anti & Blocks cellular translation & Atasheva et al. 2012, 2014 \\
\hline PARP11/ARTD11 & Mono & $\begin{array}{l}\text { VSV } \\
\text { HSV-1 }\end{array}$ & $\begin{array}{l}\text { Pro } \\
\text { Pro }\end{array}$ & $\begin{array}{l}\text { Targets IFNAR for degradation, leading } \\
\text { to decreased IFN production }\end{array}$ & Guo et al. 2019 \\
\hline
\end{tabular}

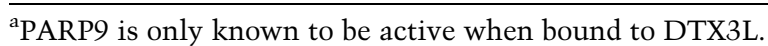

(Green) DNA-dependent PARPs; (blue) ZnF PARPs; (yellow) macro-PARPs; (orange) other-PARPs.

(HIV-1) Human immunodeficiency virus; (MLV) murine leukemia virus, (MPSV) myeloproliferative sarcoma virus; (EBV) Epstein-Barr virus; (KSHV) Kaposi's sarcoma herpesvirus; (PRRSV) porcine reproductive and respiratory syndrome virus; (HSV-1) herpes simplex virus-1; (IAV) influenza A virus; (SINV) sindbis virus; (VEEV) Venezuelan equine encephalitis virus; (RV) rubella virus; $(\gamma$-2 HV) $\gamma$-2 herpesvirus; ( $\gamma \mathrm{HV}-68)$ murine $\gamma$-herpesvirus-68; (EMCV) encephalomyocarditis virus; (VSV) vesicular stomatitis virus; (CHIKV) chikungunya virus; (ZIKV) Zika virus; (MHV) murine hepatitis virus; (ALV-J) avian leukosis virus subgroup J; (SFV) Semliki forest virus; (RRV) Ross River virus; (EBOV) Ebola virus; (MARV) Marburg virus; (EV-A71) enterovirus strain A71; (HBV) hepatitis B virus.

constituents of stress granules (Leung et al. 2011). It has been proposed that polyADP-ribose facilitates the concentration of RNA-binding proteins in stress granules and other nonmembranous structures and thereby promote their oligomerization (Leung 2014).
Some virus families encode for a macrodomain protein that reverses cellular ADP-ribosylation

Several decades ago, a conserved domain was identified in all coronaviruses (CoVs), togaviruses, and hepatitis E virus 
that was termed the " $\mathrm{X}$ " domain (Gorbalenya et al. 1991; Koonin et al. 1992). These domains are structurally homologous to the nonhistone part of the macroH2A protein and are now known as macrodomains (Allen et al. 2003). Macrodomains from all three viral families bind monoand poly-ADP-ribose, and can efficiently remove mono-ADP-ribose from proteins by hydrolysis, strongly indicating a role for ADP-ribosylation in either promoting or inhibiting the replication of these viruses (Egloff et al. 2006; Li et al. 2016). Several studies on the CoV and alphavirus macrodomains have established that this protein domain is critical for either replication or pathogenesis (Eriksson et al. 2008; Park and Griffin 2009; Fehr et al. 2015, 2016; McPherson et al. 2017). Recent studies using chikungunya virus (CHIKV) macrodomain mutants showed that macrodomain ADP-ribose binding facilitated initiation of virus replication, while hydrolase activity was essential for the amplification of replication complexes (Abraham et al. 2018). Infection with ADP-ribosylhydrolase (ARH)-deficient CoVs, including severe acute respiratory syndrome (SARS)-CoV and murine hepatitis virus (MHV), led to higher levels of IFN and other cytokines, indicating that it may block the innate immune response (Fehr et al. 2016; Grunewald et al. 2019a). The ARH-deficient MHV replicates poorly in primary macrophages, and importantly, this defect could be partially rescued by PARP inhibitors, directly indicating PARPs in the antiviral response to CoVs (Grunewald et al. 2019a). However, it remains unknown what proteins may be targeted by the viral macrodomains (for reviews, see Fehr et al. 2018; Leung et al. 2018).

The roles of PARP1 and the Tankyrase PARPs in virus replication.

Some of the first reports of PARPs and ADP-ribosylation impacting virus infection focused on the role of PARP1 on retrovirus and HIV-1 integration and replication. Gäken et al. (1996) first demonstrated that PARP inhibitors led to reduced retroviral integration into host chromatin. They further used antisense oligonucleotides and overexpression of dominant-negative PARP1 to confirm that PARP activity is required for integration of retroviral vectors. Other groups further demonstrated the importance of PARP activity in retrovirus and HIV-1 integration into host chromosomes using siRNA transfected and PARP1-deficient cells (Ha et al. 2001; Kameoka et al. 2005). Mechanistically, it was suggested that PARP1 may help resolve a 4- to 6-bp gap in the genome produced during integration (Ha et al. 2001). PARP1 activity may also impact HIV-1 transcription and replication (Kameoka et al. 1999, 2004). However, these results have been confounded by other reports that demonstrated either no evidence that PARP1 was required for efficient HIV-1 integration or replication (Baekelandt et al. 2000; Ariumi et al. 2005), or evidence that PARP1 can repress HIV-1 or retrovirus infection (Parent et al. 2005; Bueno et al. 2013). Bueno et al. (2013) found that PARP1 inhibited retroviral infection in a chicken B lymphoblastoid cell line, while Parent et al. (2005) showed that PARP1 could bind to the transactivation response element (TAR) and inhibit HIV-1 transcription by competing with TAR for binding to $\mathrm{p}$-TEF2b. The impact of PARP1 on HIV-1 infection remains controversial and is likely context-dependent.

In addition to its role in regulating retrovirus replication, PARylation enhances and represses several other viruses. This includes herpesviruses, where PARPs have a wide range of effects. PARP1 and the tankyrase PARP5a modify the EBV protein EBNA1. PARylation of EBNA1 causes it to dissociate from the dyad symmetry elements, which restricts OriP binding and impairs the maintenance of the viral episome during latency (Deng et al. 2005; Tempera et al. 2010). PARP1 also binds to the TR sequences in KSHV, which leads to reduced viral genome levels during latency. PARP1 and the Ste-20-like kinase hKFC synergistically bind to and ADP-ribosylate/phosphorylate the $\gamma$-2 herpesvirus replication and transcription activator protein (RTA) (Fig. 4A). These interactions suppress RTA-mediated transcriptional activation and KSHV lytic reactivation (Gwack et al. 2003). Two mechanisms have been described by which $\gamma$-herpesviruses counter PARP1 activity. First, it was found that ORF49 of $\gamma \mathrm{HV}-68$ binds to PARP1, preventing it from interacting with RTA (Fig. 4B). In addition, the processivity factor of $\mathrm{KSHV}$ and $\gamma \mathrm{HV}-68, \mathrm{PF}-8$, binds to and targets PARP1 for degradation, which reduces PARylated RTA and enhances virus replication (Fig. 4C; Noh et al. 2012; Chung et al. 2015). In contrast to the antiviral effects of PARPs during $\gamma$-herpesvirus infection, PARP activity seems to promote the replication

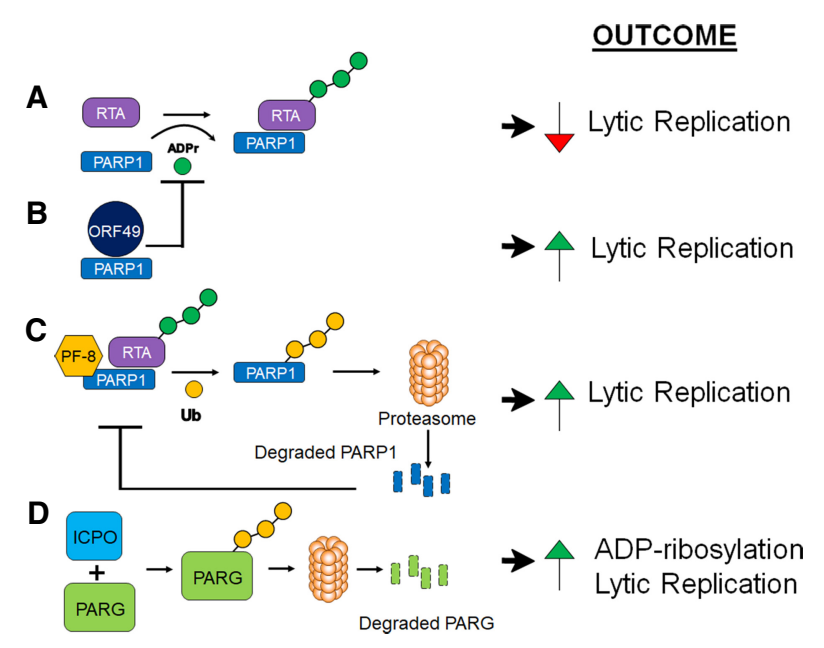

Figure 4. Mechanisms used by herpesviruses to affect PARylation and their impact on replication. (A) PARP-1 can bind to and ADP-ribosylate the $\gamma \mathrm{HV}$ RTA, which inhibits its ability to initiate lytic replication. (B) The $\gamma \mathrm{HV}-68$ protein ORF49 binds to PARP1 and prevents it from interacting with and ADP-ribosylating RTA, which allows RTA to initiate viral gene transcription. $(C)$ The KSHV and $\gamma \mathrm{HV}-68$ PF- 8 proteins bind to PARP1 and target it for ubiquitination and degradation. This again prevents ADP-ribosylation of RTA, which allows it to initiate lytic replication. $(D)$ The HSV-1 ICP0 protein targets PARG for ubiquitination and degradation, resulting in enhanced PARylation during infection and increased replication. (ADPr) ADP-ribose; (Ub) ubiquitin. 
of HSV-1, the prototype $a$-herpesvirus. PARP5a (Tankyrase-1) expression was increased and it was translocated to the nucleus during HSV-1 infection. Knockdown of both PARP5a and PARP5b resulted in a threefold to fourfold decrease in virus replication, and inhibition of their catalytic activity with XAV-939 resulted in a greater than $1-\log$ reduction in virus replication (Li et al. 2012). To further indicate that PARP activity is important for virus replication, HSV-1 infection significantly increased PARylation. The ICP0 protein targets nuclear forms of PAR glycohydrolase (PARG), the enzyme that degrades PAR, for ubiquitination and degradation, providing a possible mechanism for the dramatic increase in PARylation during infection (Fig. 4D; Grady et al. 2012).

Finally, poly-ADP-ribosylation is implicated as having proviral activities in several viral systems. PARP inhibitors have led to greatly reduced infectivity of adenoviruses, possibly through the ADP-ribosylation of their core proteins (Déry et al. 1986). PARP inhibitors also inhibit JC virus replication (Nukuzuma et al. 2013). PARP1 binds to the porcine reproductive and respiratory syndrome virus (PRRSV) nucleocapsid protein, and again, PARP inhibitors restricted the replication of PRRSV in cell culture (Liu et al. 2015b). The nucleocapsid protein of the related coronaviruses is also ADP-ribosylated, however the impact of this modification on virus replication or pathogenesis remains unknown (Grunewald et al. 2018). Last, PARP activity is required for efficient activity of the RNA polymerases derived from multiple strains of influenza virus, indicating a potential proviral role for ADPribosylation during influenza infection (Bortz et al. 2011). In summary, PARylation has a variety of different functions that can both repress and enhance virus replication.

The roles of nonenzymatic and mono-ADPribosylating $P A R P S$ in virus replication and the antiviral response.

Nonenzymatic and mono-ADP-ribosylating PARPs have a variety of roles in promoting or inhibiting virus replication. This class of PARPs include the zinc finger $(\mathrm{ZnF})$ PARPs (7, 12, and 13), the macrodomain-containing PARPs $(9,14$, and 15), and several PARPs that do not fit into a specific category $(4,6,8,10$, and 11$)$. Here, we discuss what is known about each of these PARPs in the innate immune response to viruses.

\section{CCCH ZnF PARPs}

ZnF PARPs contain one or more ZnF domains. These domains are small protein motifs that enable these PARPs to bind RNA. All three ZnF PARPs use this domain to interact with viral RNA and inhibit either translation or degrade viral RNA, though the specific RNA sequence that each PARP binds to is likely unique. In addition, all three ZnF PARPs use either the enzymatic or nonenzymatic functions in their PARP domain to impact the innate immune response or virus replication.
PARP13 (ZnF antiviral protein) PARP13, or ZnF antiviral protein (ZAP), was one of the first PARPs identified to have antiviral activities when, in a screen for antiviral ISGs, it was found to potently inhibit murine leukemia virus (MLV) replication (Gao et al. 2002). Somewhat surprisingly, ZAP lacks the triad motif (H-Y-E) needed for catalytic activity and has no auto-ADP-ribosylating activity (Kleine et al. 2008). As such, most of its antiviral activity is independent of ADP-ribosylation. Since its discovery, ZAP has been shown to inhibit the replication of several viral families, including retroviruses, alphaviruses, filoviruses, picornaviruses, herpesviruses, arteriviruses, orthomyxoviruses, flaviviruses, and hepatitis B virus (Bick et al. 2003; Muller et al. 2007; Zhu et al. 2011; Wang et al. 2012; Xuan et al. 2012; Mao et al. 2013; Xuan et al. 2013; Li et al. 2015, 2015a; Chiu et al. 2018; Xie et al. 2018; Zhao et al. 2019). ZAP is transcribed into four different isoforms, with ZAPL and ZAPS being the most studied (Li et al. 2019). ZAPL contains the inactive PARP or catalytic domain, while ZAPS does not. ZAPL tends to have greater antiviral activity, and this may be due, at least in part, to prenylation of the PARP domain /Charron et al. 2013; Schwerk et al. 2019). In addition to the PARP domain, ZAP contains four ZnF-binding domains and a single WWE domain. ZAP uses its ZnF-binding domains to bind to viral RNA and recruits both the poly(A)-specific ribonuclease (PARN) and the RNA exosome to degrade the viral RNA (Guo et al. 2007). It also inhibits translation by blocking the interaction between eIF4G and eIF4A, and its ability to block translation is required for it to degrade RNA. In addition, ZAP antiviral activity is enhanced by the ubiquitin ligase activity of TRIM25. TRIM25 binds to ZAP and ubiquitinates unknown proteins to enhance the antiviral activity of ZAP (Li et al. 2017; Zheng et al. 2017).

ZAP targets HIV RNAs for degradation, and prefers to target CG dinucleotides (Takata et al. 2017). Consistent with this, an HIV-1 mutant with an increased CG content replicated very poorly in MT4 cells, but that replication was restored in ZAP-deficient cells. In addition, ZAP targets the 3' UTR of Japanese encephalitis virus (JEV), which contains a high CG content (Chiu et al. 2018). Interestingly, it appears many viruses maintain a low CG dinucleotide level, and the level of ZAP sensitivity of several viruses mildly correlates with their CG dinucleotide content (Takata et al. 2017). However, ZAP sensitivity of a panel of alphaviruses does not correlate with the CG dinucleotide content found in their genome or individual viral genes, suggesting that the CG dinucleotide motif is not the only determinant for ZAP recognition $(\mathrm{Li}$ et al. 2019). The localization of ZAP to stress granules also appears to be functionally important for its antiviral activity against alphaviruses, as ZAP mutants that do not localize to SGs are unable to block SINV replication (Law et al. 2019). In vivo, Zap knockout (Zc3hav1 $\left.{ }^{-/-}\right)$mice showed enhanced replication of SINV in 10-d-old mice as expected (Kozaki et al. 2015). Though surprisingly, in 23-d-old weanling pups it was shown that a neurovirulent strain of SINV can use ZAP to decrease its replication in initially infected cells in vivo such that it prevents immune 
recognition, allowing the virus to spread to the central nervous system (CNS) and promote disease (Wang et al. 2016).

In addition, different studies have found conflicting results regarding the ability of ZAP to impact the innate immune response. It was originally found that ZAPS, but not ZAPL, potentiates RIG-I-dependent type I interferon (IFNI) production in human cells by binding to RIG-I via its $\mathrm{ZnF}$ domains and promoting its oligomerization (Fig. 1A; Hayakawa et al. 2011; Chiu et al. 2018). However, ZAP does not appear to enhance RIG-I-dependent IFN-I production in mouse cells (Lee et al. 2013). More recent data indicate that ZAPS may also reduce IFN mRNA by binding to the $3^{\prime}$ UTR of IFN mRNA and targeting it for degradation (Fig. 1A; Schwerk et al. 2019). It is conceivable that ZAP-S uses both functions but in a context-dependent manner.

While ZAPL does not contain an active PARP domain, in some cases it is required for the ADP-ribosylation of proteins. For instance, the $\mathrm{C}$ terminus of ZAPL binds to the influenza virus polymerase proteins $\mathrm{PB} 2$ and $\mathrm{PA}$, which causes their subsequent poly-ADP-ribosylation, ubiquitination, and degradation (Liu et al. 2015a). It is unknown which PARP and E3 ubiquitin ligase mediates these effects. Knockdown of ZAPL modestly increased influenza virus replication in cell culture, though it is not clear whether this is due to its ability to bind and target PB2 and PA for degradation. Interestingly, this ZAPL activity was countered by the $\mathrm{PB} 1$ protein, which bound to ZAPL preventing the ubiquitination of $\mathrm{PB} 2$ and $\mathrm{PA}$, demonstrating that the virus has evolved ways to neutralize the antiviral activity of ZAP (Fig. 5A). In addition to $\mathrm{PB} 1$, several other viral proteins have been found to counter ZAP using multiple mechanisms (Fig. 5B-D). Influenza A NS1 prevents ZAP-S from binding to its target RNA (Tang et al. 2017), $\gamma$ HV-68 RTA disrupts the intermolecular interaction of ZAP (Xuan et al. 2013), HSV-1 UL41 degrades ZAP mRNA (Su et al. 2015), and, finally, the enterovirus (EV)-71 3C protease cleaves ZAP protein (Xie et al. 2018). Due to its broad-spectrum antiviral activity, it is likely there are even more viral proteins that function to counter ZAP.

PARP12 PARP12 is a mono-ADP-ribosyltransferase and has four or five $\mathrm{N}$-terminal CCCH-type zinc finger $(\mathrm{ZnF})$ domains that are important for RNA binding, one or two WWE domains in the middle of the protein that are important for ADP-ribose binding, and a PARP domain at the $\mathrm{C}$ terminus, which provides the protein with mono-ADPribosylating activity (Welsby et al. 2014). There are two splice forms of PARP12 mRNA, PARP12L, and PARP12S (Atasheva et al. 2012). PARP12L contains both the ZnF domains and the PARP catalytic domain, while PARP12S has the $\mathrm{ZnF}$ domains but lacks the PARP catalytic domain.

As described above, PARP12 translocates to cytoplasmic stress granules upon cell stress (Leung et al. 2011; Welsby et al. 2014). PARP12 initially localizes to the trans-Golgi network (TGN) and translocates to stress granules during stress stimuli in several different cell

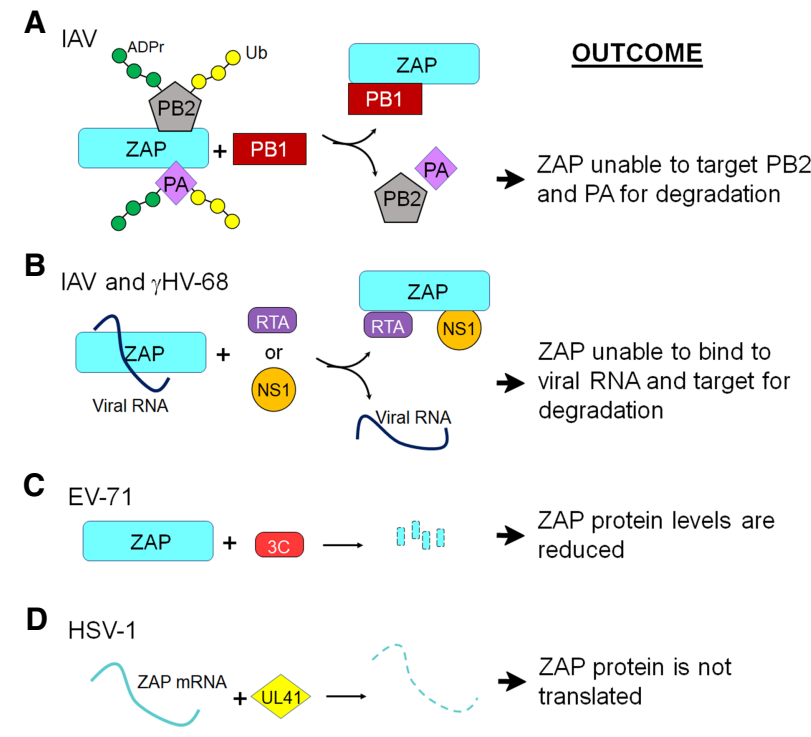

Figure 5. Viral mechanisms of ZAP antagonism. $(A)$ IAV protein $\mathrm{PB} 1$ binds to ZAP, which prevents its interaction with the PA and $\mathrm{PB} 2$ proteins that otherwise would lead to PARylation, ubiquitination, and degradation of these proteins. (B) IAV NS1 and $\gamma \mathrm{HV}$ 68 RTA proteins interact with ZAP, preventing its association with viral RNA. $(C)$ The EV-71 3C protease cleaves ZAP to prevent it from accumulating. (D) HSV-1 UL41 protein cleaves ZAP mRNA to prevent its translation. (ADPr) ADP-ribose; (Ub) ubiquitin.

types. This activity has been linked to the $\mathrm{ZnF}$ domains, as mutations in the $\mathrm{ZnF}$ domains abrogated the ability of PARP12 to move to stress granules (Welsby et al. 2014). The translocation of PARP12 may also depend on PARP1 acting as a stress sensor in the nucleus, as an increase in unconjugated PAR is a key factor that promotes the recruitment of PARP12 to stress granules (Catara et al. 2017). The translocation of PARP12 to stress granules is reversible, as it relocates back to the Golgi once the stress is relieved.

The antiviral role of PARP12 was first described in an overexpression screen, where it mildly inhibited the replication of both VSV and MHV-68 (Liu et al. 2012b). Shortly after this, another study found that PARP12 was differentially expressed in cells that cleared VEEV replication compared with those that were persistently infected (Atasheva et al. 2012). Further analysis showed that PARP12L, but not PARP12S, expression from a VEEV replicon or virus restricts VEEV replication, as well as several other viruses including Sindbis virus (SINV), encephalomyocarditis virus (EMCV), vesicular stomatitis virus (VSV), Rift Valley fever virus (RVFV), and chikungunya virus (CHIKV). Subsequently, this group showed that PARP12 strongly inhibited both cellular and viral translation (Atasheva et al. 2014). Immunoprecipitation with PARP12 identified several ribosomal proteins and translation and elongation factors, indicating that PARP12 interacts with ribosomes. Interestingly, PARP12 required its enzymatic activity to block translation, but not to inhibit virus 
replication, indicating that PARP12 may use distinct mechanisms to block virus replication and cellular translation.

Additionally, PARP12 was identified in a screen for ISGs that inhibit Zika virus (ZIKV) (Li et al. 2018). Using both knockout cells and overexpression, the authors showed that PARP12 was both necessary and sufficient for the inhibition of ZIKV replication. PARP12 was required for the ADP-ribosylation, ubiquitination, and subsequent degradation of ZIKV NS1 and NS3 proteins. This activity did not require either the ZnF or WWE domains of PARP, but did require its catalytic domain, as an inactive catalytic domain reversed the regulatory effects of PARP12 on viral protein degradation. Interestingly, NS1 and NS3 appeared to be poly-ADP-ribosylated, indicating that PARP12 may work with another PARP to mediate the poly-ADP-ribosylation of these proteins. PARP12 also has a role in the restriction of coronavirus (CoV) replication, as siRNA knockdown of PARP12 partially restored replication of MHV lacking the ADPribosylhydrolase (ARH) activity of the CoV macrodomain (Grunewald et al. 2019a). The mechanism used by PARP12 to restrict MHV replication remains unknown. Finally, PARP12 was also shown to enhance NF- $\mathrm{kB}$ signaling, possibly by interacting with TRIF (Fig. 1A; Welsby et al. 2014).

PARP7 (TiPARP) PARP7, also known as tetrachlorodibenzo-p-dioxin (TCDD)-inducible poly-ADP-ribose polymerase (TiPARP), has a single $\mathrm{ZnF}$ domain that mediates RNA binding. It also has a WWE domain and a PARP catalytic domain capable of mono-ADP-ribosylation (Kozaki et al. 2017).

Like PARP12, TiPARP was also shown to block VEEV replication and inhibit cellular translation when transduced into cells by a VEEV replicon (Atasheva et al. 2014). In a separate study, siRNA knockdown of TiPARP in U373 human astrocyte cells led to increased replication of SINV and rubella virus replication (Kozaki et al. 2017). The increase in SINV replication was also demonstrated in TiParp ${ }^{-/-}$mice. TiPARP-mediated inhibition of SINV was dependent on its ZnF domain, which binds to SINV RNA and recruits RNA degradation factors to sites of viral replication. This suggests that TiPARP recognizes specific virus RNAs for degradation, however the target specificity of TiPARP is still unknown.

TiPARP also has proviral effects in addition to its antiviral functions. TiPARP negatively regulates the type I IFN response by ADP-ribosylating TBK1 (Fig. 1A; Yamada et al. 2016). The ADP-ribosylation of the kinase domain of TBK1 suppresses IFN production. It was suggested that negative regulation of IFN production by TiPARP may help protect the cell from the harmful effects of type I IFN. The same study found that the loss of TiPARP led to decreased IAV replication, which strongly correlated with increased IFN-I production. Our group has also found that siRNA knockdown of TiPARP led to decreased replication of MHV and increased IFN-I production, further indicating TiPARP as a proviral factor for some viruses (Grunewald et al. 2019a,b). However, it remains unclear whether the ability of TiPARP to enhance MHV or IAV replication is tied to its ability to block the IFN-I response.

\section{Macrodomain-containing PARPS}

The macro PARPs contain two (PARP9/PARP15) or three (PARP14) macrodomains that mediate binding to ADP-ribose, as described above. While some macrodomains can cleave ADP-ribose from a substrate, it is likely that macrodomains within these PARP proteins only bind ADP-ribose. All three macro PARPs are rapidly evolving (Daugherty et al. 2014), and PARP15 has been identified in stress granules (Leung et al. 2011); however, direct evidence of their involvement in virus infections is limited. No study has identified a role for PARP15 in modulating virus infection or the innate immune response, and thus it will not be discussed further.

PARP9 (BAL1) PARP9 was originally termed B-aggressive lymphoma 1 gene (BAL1) as it was identified as a risk factor for large diffuse B-cell lymphomas (Aguiar et al. 2005). It is catalytically inactive, at least when expressed by itself, but can ADP-ribosylate ubiquitin in the presence of an E3 ubiquitin ligase, DTX3L (Yang et al. 2017). As described above, PARP9 promotes STAT1 phosphorylation, proinflammatory gene expression, and differentiation into M1-like macrophages (Iwata et al. 2016). In the antiviral response, PARP9 expression in malignant B-cell lymphoma lines can lead to widespread induction of ISG expression (Juszczynski et al. 2006). Zhang et al. (2015) found that the complex of PARP9 and DTX3L attached to STAT1 to mediate the hyper-responsiveness of a mutant STAT1 protein (STAT1-CC). The PARP9-DTX3L complex ubiquitinates histone proteins, most notably H2BJ, which led to chromatin remodeling and enhanced expression of at least a subset of ISGs (Fig. 1B). This interaction was necessary and sufficient to inhibit the replication of multiple viruses, including EMCV, IAV, and SINV. The PARP9-DTX3L complex also ubiquitinates the EMCV $3 \mathrm{C}$ protease, which led to its degradation, but this effect was mostly, if not completely, due to DTX3L activity.

PARP14 (COaST-6) PARP14 was originally identified as Collaborator of STAT6 (CoaST6) (Goenka and Boothby 2006). It has a range of effects on cell physiology and immunity that were largely anti-inflammatory (Cho et al. 2011, 2013; Barbarulo et al. 2013; Vyas et al. 2013; Iansante et al. 2015; Iwata et al. 2016; Krishnamurthy and Kaplan 2016). In the antiviral response, PARP14 instead is required to enhance IFN-I production in RAW cells (transformed peritoneal macrophages) following LPS treatment (Caprara et al. 2018), in primary macrophage cells during CoV infection, and following treatment of human A549 cells with poly(I:C) (Grunewald et al. 2019a). Following LPS treatment, PARP14-deficient cells showed similar levels of IRF-3 phosphorylation and nuclear translocation, but had reduced levels of Pol II recruited to the promoters of IRF-3-dependent genes (Caprara et al. 2018). There was also a dramatic reduction in $\mathrm{H} 3 \mathrm{~K} 27$ 
acetylation, a known marker of active promoters and enhancers (Fig. 1A). It is unclear whether this function of PARP14 is dependent on its catalytic activity. It is also not yet known whether PARP14 has the same function in the cellular response to virus infection or poly(I:C). These two studies also found that PARP14 was required to restrict the replication of $S$. typhimurium and an ARH-deficient MHV, though it is not known whether the ability of PARP14 to inhibit these pathogens is tied to its role in up-regulating IFN production or whether these are distinct functions of PARP14. It is important to note that these experiments were done with undifferentiated or M0 macrophages, while other studies where PARP-14 was found to have anti-inflammatory functions used M1 or M2 macrophages, differentiated by further IFN- $\gamma$ or IL- 4 treatment. This suggests that PARP14 function is likely context-dependent.

\section{Other PARPS}

The final class of PARPs do not fit into any of the other defined classes of PARPs, have no similar domains other than the PARP domain, and are thus simply termed "other PARPs." These PARPs include PARPs 4, 6, 8, 10, 11, and 16. PARP6 and PARP8 have no defined domains besides their PARP domain, and neither have a known role in the immune response. PARP4, while rapidly evolving as described earlier, has not been reported to have any direct antiviral or proviral activity. PARP16 promotes ER stress responses by ADP-ribosylating IRE1 $\alpha$ and PERK (Jwa and Chang 2012), and also ADP-ribosylates Karyopherin $\beta 1$, indicating a potential role in nuclear transport (Di Paola et al. 2012). However, it also has no known antiviral activities or impact on the innate immune response. Here we focus on PARP10 and PARP11.

PARP10 PARP10 contains both an RNA recognition motif (RRM), nuclear import and export signals, and two ubiquitin-interacting motifs (UIM) in addition to its catalytic domain (Verheugd et al. 2013) and is highly up-regulated by IFN (Eckei et al. 2017; Grunewald et al. 2019a). Along with PARP12 and PARP7, it inhibits VEEV replication and blocks protein translation when expressed from a VEEV replicon (Atasheva et al. 2014). PARP10 also blocks NF- $\kappa \mathrm{B}$ signaling and the production of proinflammatory cytokines (Verheugd et al. 2013). Mechanistically, the UIM of PARP10 interacts with K63-linked ubiquitin chains and NEMO. PARP10 ADP-ribosylates NEMO and prevents its polyubiquitination, which ultimately blocks NF- $\kappa B$ from translocating to the nucleus to activate gene expression (Fig. 1A). It remains unknown whether this function of PARP10 impacts host-pathogen interactions or whether it functions in other contexts.

PARP11 PARP11 is the second smallest PARP protein (PARP16 is the smallest), with only a single WWE domain in addition to its ART domain, and is also highly up-regulated by IFN (Grunewald et al. 2019a). Recently, PARP11 was shown to block IFN signaling by ADP-ribosylating the E3 ubiquitin ligase $\beta$-transducin repeat-containing protein $(\beta$-TrCP), which lead to the ubiquitination and degradation of the interferon $\alpha / \beta$ receptor (IFNAR) (Fig. 1B; Guo et al. 2019). siRNA silencing of PARP11 or treatment with rucaparib, a pan-PARP inhibitor used in advanced ovarian cancer, inhibited the replication of VSV and HSV-1. While normally known to inhibit PARP1/2, at the concentrations of drug used in this study rucaparib appeared to preferentially target PARP11. Interestingly, following infection in vivo, rucaparib enhanced IFN-I signaling, reduced VSV replication in multiple organs, and led to better outcomes for the mice infected with either VSV or HSV-1. These data indicate that PARP11-specific inhibitors could be a useful means of treating specific viral infections.

In summary, several of the nonenzymatic or monoADP-ribosylating PARPs are potent antiviral proteins that are able to inhibit viruses from several different viral families. However, some do contain activities that promote virus replication. While some mechanisms are known, including blocking translation, degrading RNA, and targeting viral or host proteins for ubiquitination and degradation, many mechanisms are still unknown. However, recent reports are making it clear that in many, but not all cases, ADP-ribosylation is tied to protein homeostasis, either through mediating translation or ubiquitination-dependent protein degradation. In addition, several studies have identified multiple points where the innate immune response is modulated by PARPs and ADP-ribosylation (Fig. 1). The identification of similar and potentially novel processes mediated by PARPs in virus infections will likely be uncovered in the near future.

\section{Final remarks}

With the advent of new mass spectrometry techniques and improved tools for detecting ADP-ribose, the last decade has seen an explosion in our understanding of how PARPs and ADP-ribose impact not just immunity, but biology in general. This technological development is exponential, which will further facilitate PARP research in the future. PARP inhibitors are being tested in the clinic for chemotherapy, so it is likely that PARP inhibitors or agonists could be useful for treating immune disorders as well. However, developing PARP-specific inhibitors or agonists will be challenging. There is still a long way to go before we fully understand how PARPs function both in cell culture and in vivo to target them for the treatment of infections or immune diseases. Additional PARPdeficient animals and specific inhibitors are needed to gain a better knowledge of how PARPs impact pathogenesis from infection or immune-mediated diseases. While PARPs are structurally and functionally distinct, specificity and off-target effects of PARP inhibitors remain incompletely understood; thus, further characterization of each compound is necessary.

Accumulating clinical and scientific evidence supports a theory that inflammation promotes various global health threats such as myocardial infarction. However, mechanisms of macrophage activation, for instance, 
remain obscure. Recent understanding that macrophages are highly heterogeneous has added to the complexity of inflammation. What is the role of each PARP in inflammation via an enzymatic activity-dependent or independent mechanism? What is a specific function of each domain in macrophage activation? Furthermore, additional roles for PARPs in the antiviral response are likely to exist, especially for PARPs that are under strong positive selection pressure, but have yet to be associated with a specific biological activity. In several cases the mechanism used by PARPs to inhibit specific viruses remain unknown. It is also intriguing that several IFN-induced PARPs have been shown to enhance virus replication. Could this be a mechanism by the host to maintain a minimal amount of virus replication in vivo so that the immune system can be appropriately activated? The answers to these and many other questions will be of great interest to PARP researchers, immunologists, and microbiologists as they are likely to uncover unique cellular processes regulated by ADP-ribosylation that could lead to the identification of novel therapeutic targets for infections or immune-mediated diseases.

\section{Acknowledgments}

We thank Melody Li for critically reading this manuscript. This work was supported in part by National Institutes of Health grants CoBRE P20 GM113117-02 and K22 AI134993-01 to A.R.F. and R01 HL126901 to M.A., and by the Kowa Company, Ltd. (M.A.).

\section{References}

Abraham R, Hauer D, McPherson RL, Utt A, Kirby IT, Cohen MS, Merits A, Leung AKL, Griffin DE. 2018. ADP-ribosylbinding and hydrolase activities of the alphavirus nsP3 macrodomain are critical for initiation of virus replication. Proc Natl Acad Sci 115: E10457-E10466. doi:10.1073/pnas .1812130115

Aday AW, Ridker PM. 2019. Targeting residual inflammatory risk: a shifting paradigm for atherosclerotic disease. Front Cardiovasc Med 6: 16. doi:10.3389/fcvm.2019.00016

Aguiar RC, Yakushijin Y, Kharbanda S, Salgia R, Fletcher JA, Shipp MA. 2000. BAL is a novel risk-related gene in diffuse large B-cell lymphomas that enhances cellular migration. Blood 96: 4328-4334. doi:10.1182/blood.V96.13.4328

Aguiar RC, Takeyama K, He C, Kreinbrink K, Shipp MA. 2005. $\mathrm{B}$-aggressive lymphoma family proteins have unique domains that modulate transcription and exhibit poly(ADP-ribose) polymerase activity. I Biol Chem 280: 33756-33765. doi:10 .1074/jbc.M505408200

Aldinucci A, Gerlini G, Fossati S, Cipriani G, Ballerini C, Biagioli T, Pimpinelli N, Borgognoni L, Massacesi L, Moroni F, et al. 2007. A key role for poly(ADP-ribose) polymerase-1 activity during human dendritic cell maturation. I Immunol 179: 305-312. doi:10.4049/jimmunol.179.1.305

Allen MD, Buckle AM, Cordell SC, Löwe J, Bycroft M. 2003. The crystal structure of AF1521 a protein from Archaeoglobus fulgidus with homology to the non-histone domain of macroH2A. J Mol Biol 330: 503-511. doi:10.1016/S0022-2836(03) 00473-X
Ariumi Y, Turelli P, Masutani M, Trono D. 2005. DNA damage sensors ATM, ATR, DNA-PKcs, and PARP-1 are dispensable for human immunodeficiency virus type 1 integration. J Virol 79: 2973-2978. doi:10.1128/JVI.79.5.2973-2978.2005

Atasheva S, Akhrymuk M, Frolova EI, Frolov I. 2012. New PARP gene with an anti-alphavirus function. J Virol 86: 8147-8160. doi:10.1128/JVI.00733-12

Atasheva S, Frolova EI, Frolov I. 2014. Interferon-stimulated poly (ADP-ribose) polymerases are potent inhibitors of cellular translation and virus replication. I Virol 88: 2116-2130. doi:10.1128/JVI.03443-13

Baekelandt V, Claeys A, Cherepanov P, De Clercq E, De Strooper B, Nuttin B, Debyser Z. 2000. DNA-dependent protein kinase is not required for efficient lentivirus integration. J Virol 74: 11278-11285. doi:10.1128/JVI.74.23.11278-11285.2000

Bai P, Virág L. 2012. Role of poly(ADP-ribose) polymerases in the regulation of inflammatory processes. FEBS Lett 586: 37713777. doi:10.1016/j.febslet.2012.09.026

Barbarulo A, Iansante V, Chaidos A, Naresh K, Rahemtulla A, Franzoso G, Karadimitris A, Haskard DO, Papa S, Bubici C. 2013. Poly(ADP-ribose) polymerase family member 14 (PARP14) is a novel effector of the JNK2-dependent pro-survival signal in multiple myeloma. Oncogene 32: 4231-4242. doi:10.1038/onc.2012.448

Bercovici N, Guérin MV, Trautmann A, Donnadieu E. 2019. The remarkable plasticity of macrophages: a chance to fight cancer. Front Immunol 10: 1563. doi:10.3389/fimmu.2019.01563

Berger NA, Besson VC, Boulares AH, Bürkle A, Chiarugi A, Clark RS, Curtin NJ, Cuzzocrea S, Dawson TM, Dawson VL, et al. 2018. Opportunities for the repurposing of PARP inhibitors for the therapy of non-oncological diseases. Br I Pharmacol 175: 192-222. doi:10.1111/bph.13748

Berton G, Sorio C, Laudanna C, Menegazzi M, Carcereri De Prati A, Suzuki H. 1991. Activation of human monocyte-derived macrophages by interferon $\gamma$ is accompanied by increase of poly(ADP-ribose) polymerase activity. Biochim Biophys Acta 1091: 101-109. doi:10.1016/0167-4889(91)90228-P

Bick MJ, Carroll JW, Gao G, Goff SP, Rice CM, MacDonald MR. 2003. Expression of the zinc-finger antiviral protein inhibits alphavirus replication. J Virol 77: 11555-11562. doi:10.1128/ JVI.77.21.11555-11562.2003

Bohio AA, Sattout A, Wang R, Wang K, Sah RK, Guo X, Zeng X, Ke Y, Boldogh I, Ba X. 2019. . c-Abl-mediated tyrosine phosphorylation of PARP1 is crucial for expression of proinflammatory genes. I Immunol 203: 1521-1531. doi:10.4049/ jimmunol.1801616

Bortz E, Westera L, Maamary J, Steel J, Albrecht RA, Manicassamy B, Chase G, Martinez-Sobrido L, Schwemmle M, Garcia-Sastre A. 2011. Host- and strain-specific regulation of influenza virus polymerase activity by interacting cellular proteins. MBio 2: e00151-11. doi:10.1128/mBio.00151-11

Bueno MT, Reyes D, Valdes L, Saheba A, Urias E, Mendoza C, Fregoso OI, Llano M. 2013. Poly(ADP-ribose) polymerase 1 promotes transcriptional repression of integrated retroviruses. I Virol 87: 2496-2507. doi:10.1128/JVI.01668-12

Cameron AM, Castoldi A, Sanin DE, Flachsmann LJ, Field CS, Puleston DI, Kyle RL, Patterson AE, Hässler F, Buescher JM, et al. 2019. Inflammatory macrophage dependence on $\mathrm{NAD}^{+}$ salvage is a consequence of reactive oxygen species-mediated DNA damage. Nat Immunol 20: 420-432. doi:10.1038/ s41590-019-0336-y

Caprara G, Prosperini E, Piccolo V, Sigismondo G, Melacarne A, Cuomo A, Boothby M, Rescigno M, Bonaldi T, Natoli G. 2018. PARP14 controls the nuclear accumulation of a subset 
of type I IFN-inducible proteins. J Immunol 200: 2439-2454. doi:10.4049/jimmunol.1701117

Catara G, Grimaldi G, Schembri L, Spano D, Turacchio G, Lo Monte M, Beccari AR, Valente C, Corda D. 2017. PARP1-produced poly-ADP-ribose causes the PARP12 translocation to stress granules and impairment of Golgi complex functions. Sci Rep 7: 14035. doi:10.1038/s41598-017-14156-8

Charron G, Li MM, MacDonald MR, Hang HC. 2013. Prenylome profiling reveals $\mathrm{S}$-farnesylation is crucial for membrane targeting and antiviral activity of ZAP long-isoform. Proc Nat1 Acad Sci 110: 11085-11090. doi:10.1073/pnas.1302564110

Chiu HP, Chiu H, Yang CF, Lee YL, Chiu FL, Kuo HC, Lin RJ, Lin YL. 2018. Inhibition of Japanese encephalitis virus infection by the host zinc-finger antiviral protein. PLoS Pathog 14: e1007166. doi:10.1371/journal.ppat.1007166

Cho SH, Goenka S, Henttinen T, Gudapati P, Reinikainen A, Eischen CM, Lahesmaa R, Boothby M. 2009. PARP-14, a member of the $\mathrm{B}$ aggressive lymphoma family, transduces survival signals in primary B cells. Blood 113: 2416-2425. doi:10 .1182/blood-2008-03-144121

Cho SH, Ahn AK, Bhargava P, Lee CH, Eischen CM, McGuinness O, Boothby M. 2011. Glycolytic rate and lymphomagenesis depend on PARP14, an ADP ribosyltransferase of the B aggressive lymphoma (BAL) family. Proc Natl Acad Sci 108: 1597215977. doi:10.1073/pnas.1017082108

Cho SH, Raybuck A, Wei M, Erickson J, Nam KT, Cox RG, Trochtenberg A, Thomas JW, Williams J, Boothby M. 2013. B cell-intrinsic and -extrinsic regulation of antibody responses by PARP14, an intracellular (ADP-ribosyl)transferase. I Immunol 191: 3169-3178. doi:10.4049/jimmunol.1301106

Chung WC, Park JH, Kang HR, Song MJ. 2015. Downregulation of poly(ADP-Ribose) polymerase 1 by a viral processivity factor facilitates lytic replication of $\gamma$ herpesvirus. I Virol 89: 96769682. doi:10.1128/JVI.00559-15

Daugherty MD, Young JM, Kerns JA, Malik HS. 2014. Rapid evolution of PARP genes suggests a broad role for ADP-ribosylation in host-virus conflicts. PLoS Genet 10: e1004403. doi:10.1371/journal.pgen.1004403

Dean P, Heunis T, Härtlova A, Trost M. 2019. Regulation of phagosome functions by post-translational modifications: a new paradigm. Curr Opin Chem Biol 48: 73-80. doi:10.1016/j .cbpa.2018.11.001

Decano JL, Aikawa M. 2018. Dynamic macrophages: understanding mechanisms of activation as guide to therapy for atherosclerotic vascular disease. Front Cardiovasc Med 5: 97. doi:10.3389/fcvm.2018.00097

Deng Z, Atanasiu C, Zhao K, Marmorstein R, Sbodio JI, Chi NW, Lieberman PM. 2005. Inhibition of Epstein-Barr virus OriP function by tankyrase, a telomere-associated poly-ADP ribose polymerase that binds and modifies EBNA1. I Virol 79: 46404650. doi:10.1128/JVI.79.8.4640-4650.2005

Déry CV, de Murcia G, Lamarre D, Morin N, Poirier GG, Weber J. 1986. Possible role of ADP-ribosylation of adenovirus core proteins in virus infection. Virus Res 4: 313-329. doi:10 .1016/0168-1702/86)90078-X

de Vries MR, Quax PHA. 2018. Inflammation in vein graft disease. Front Cardiovasc Med 5: 3. doi:10.3389/fcvm.2018 .00003

Dharwal V, Sandhir R, Naura AS. 2019. PARP-1 inhibition provides protection against elastase-induced emphysema by mitigating the expression of matrix metalloproteinases. Mol Cell Biochem 457: 41-49. doi:10.1007/s11010-019-03510-1

Di Benedetto P, Ruscitti P, Vadasz Z, Toubi E, Giacomelli R. 2019. Macrophages with regulatory functions, a possible new therapeutic perspective in autoimmune diseases. Autoimmun Rev 18: 102369. doi:10.1016/j.autrev.2019.102369

Ding L, Kim HJ, Wang Q, Kearns M, Jiang T, Ohlson CE, Li BB, Xie S, Liu JF, Stover EH, et al. 2018. PARP inhibition elicits STING-dependent antitumor immunity in Brcal-deficient ovarian cancer. Cell Rep 25: 2972-2980 5. doi:10.1016/j .celrep.2018.11.054

Di Paola S, Micaroni M, Di Tullio G, Buccione R, Di Girolamo M. 2012. PARP16/ARTD15 is a novel endoplasmic-reticulum-associated mono-ADP-ribosyltransferase that interacts with, and modifies karyopherin- $ß 1$. PLoS One 7: e37352. doi:10 .1371/journal.pone.0037352

Ditsworth D, Zong WX, Thompson CB. 2007. Activation of poly (ADP)-ribose polymerase (PARP-1) induces release of the proinflammatory mediator HMGB1 from the nucleus. I Biol Chem 282: 17845-17854. doi:10.1074/jbc.M701465200

Dunphy G, Flannery SM, Almine JF, Connolly DJ, Paulus C, Jonsson KL, Jakobsen MR, Nevels MM, Bowie AG, Unterholzner L. 2018. Non-canonical activation of the DNA sensing adaptor STING by ATM and IFI16 mediates NF- $\mathrm{kB}$ signaling after nuclear DNA damage. Mol Cell 71: 745-760 e5. doi:10.1016/j .molcel.2018.07.034

Eckei L, Krieg S, Bütepage M, Lehmann A, Gross A, Lippok B, Grimm AR, Kümmerer BM, Rossetti G, Lüscher B, et al. 2017. The conserved macrodomains of the non-structural proteins of Chikungunya virus and other pathogenic positive strand RNA viruses function as mono-ADP-ribosylhydrolases. Sci Rep 7: 41746. doi:10.1038/srep41746

Egloff MP, Malet H, Putics A, Heinonen M, Dutartre H, Frangeul A, Gruez A, Campanacci V, Cambillau C, Ziebuhr J, et al. 2006. Structural and functional basis for ADP-ribose and poly(ADP-ribose) binding by viral macro domains. J Virol 80: 8493-8502. doi:10.1128/JVI.00713-06

Eriksson KK, Cervantes-Barragan L, Ludewig B, Thiel V. 2008. Mouse hepatitis virus liver pathology is dependent on ADP-ribose-1"-phosphatase, a viral function conserved in the a-like supergroup. I Virol 82: 12325-12334. doi:10.1128/JVI.0208208

Fehr AR, Athmer J, Channappanavar R, Phillips JM, Meyerholz DK, Perlman S. 2015. The nsp3 macrodomain promotes virulence in mice with coronavirus-induced encephalitis. I Virol 89: 1523-1536. doi:10.1128/JVI.02596-14

Fehr AR, Channappanavar R, Jankevicius G, Fett C, Zhao J, Athmer J, Meyerholz DK, Ahel I, Perlman S. 2016. The conserved coronavirus macrodomain promotes virulence and suppresses the innate immune response during severe acute respiratory syndrome coronavirus infection. MBio 7: e0172116.

Fehr AR, Jankevicius G, Ahel I, Perlman S. 2018. Viral macrodomains: unique mediators of viral replication and pathogenesis. Trends Microbiol 26: 598-610. doi:10.1016/j.tim.2017.11.011

Funes SC, Rios M, Escobar-Vera J, Kalergis AM. 2018. Implications of macrophage polarization in autoimmunity. Immunology 154: 186-195. doi:10.1111/imm.12910

Gäken JA, Tavassoli M, Gan SU, Vallian S, Giddings I, Darling DC, Galea-Lauri J, Thomas MG, Abedi H, Schreiber V, et al. 1996. Efficient retroviral infection of mammalian cells is blocked by inhibition of poly(ADP-ribose) polymerase activity. I Virol 70: 3992-4000. doi:10.1128/JVI.70.6.3992-4000 .1996

Galindo-Campos MA, Bedora-Faure M, Farrés J, Lescale C, Moreno-Lama L, Martinez C, Martin-Caballero J, Ampurdanés C, Aparicio P, Dantzer F, et al. 2019. Coordinated signals from the DNA repair enzymes PARP-1 and PARP-2 promotes 
B-cell development and function. Cell Death Differ 26: 26672681. doi:10.1038/s41418-019-0326-5

Gao G, Guo X, Goff SP. 2002. Inhibition of retroviral RNA production by ZAP, a CCCH-type zinc finger protein. Science 297: 1703-1706. doi:10.1126/science.1074276

Gisterå A, Hansson GK. 2017. The immunology of atherosclerosis. Nat Rev Nephrol 13: 368-380. doi:10.1038/nrneph.2017 .51

Goenka S, Boothby M. 2006. Selective potentiation of Stat-dependent gene expression by collaborator of Stat6 (CoaSt6), a transcriptional cofactor. Proc Natl Acad Sci 103: 4210-4215. doi:10.1073/pnas.0506981103

Goenka S, Cho SH, Boothby M. 2007. Collaborator of Stat6 (CoaSt6)-associated poly(ADP-ribose) polymerase activity modulates Stat6-dependent gene transcription. I Biol Chem 282: 18732-18739. doi:10.1074/jbc.M611283200

Gomez I, Duval V, Silvestre JS. 2018. Cardiomyocytes and macrophages discourse on the method to govern cardiac repair. Front Cardiovasc Med 5: 134. doi:10.3389/fcvm.2018.00134

Gorbalenya AE, Koonin EV, Lai MM. 1991. Putative papain-related thiol proteases of positive-strand RNA viruses. Identification of rubi- and aphthovirus proteases and delineation of a novel conserved domain associated with proteases of rubi-, alpha- and coronaviruses. FEBS Lett 288: 201-205. doi:10.1016/ 0014-5793(91)81034-6

Grady SL, Hwang J, Vastag L, Rabinowitz JD, Shenk T. 2012. Herpes simplex virus 1 infection activates poly(ADP-ribose) polymerase and triggers the degradation of poly(ADP-ribose) glycohydrolase. I Virol 86: 8259-8268. doi:10.1128/JVI .00495-12

Grunewald ME, Fehr AR, Athmer J, Perlman S. 2018. The coronavirus nucleocapsid protein is ADP-ribosylated. Virology 517: 62-68. doi:10.1016/j.virol.2017.11.020

Grunewald ME, Chen Y, Kuny C, Maejima T, Lease R, Ferraris D, Aikawa M, Sullivan CS, Perlman S, Fehr AR. 2019a. The coronavirus macrodomain is required to prevent PARP-mediated inhibition of virus replication and enhancement of IFN expression. PLoS Pathog 15: e1007756. doi:10.1371/journal .ppat.1007756

Grunewald ME, Shaban MG, Mackin SR, Fehr AR, Perlman S. 2019b. Murine coronavirus infection activates $A h R$ in an IDO1-independent manner contributing to cytokine modulation and pro-viral TiPARP expression. I Virol 94: 01743-19. doi:10.1128/JVI.01743-19

Guner A, Kim HI. 2019. Biomarkers for evaluating the inflammation status in patients with cancer. J Gastric Cancer 19: 254277. doi:10.5230/jgc.2019.19.e29

Guo X, Ma J, Sun J, Gao G. 2007. The zinc-finger antiviral protein recruits the RNA processing exosome to degrade the target mRNA. Proc Natl Acad Sci 104: 151-156. doi:10.1073/pnas .0607063104

Guo T, Zuo Y, Qian L, Liu J, Yuan Y, Xu K, Miao Y, Feng Q, Chen $\mathrm{X}$, Jin L, et al. 2019. ADP-ribosyltransferase PARP11 modulates the interferon antiviral response by mono-ADP-ribosylating the ubiquitin E3 ligase $\beta$-TrCP. Nat Microbiol 4: 1872-1884. doi:10.1038/s41564-019-0428-3

Gupte R, Liu Z, Kraus WL. 2017. PARPs and ADP-ribosylation: recent advances linking molecular functions to biological outcomes. Genes Dev 31: 101-126. doi:10.1101/gad.291518.116

Gwack Y, Nakamura H, Lee SH, Souvlis J, Yustein JT, Gygi S, Kung HJ, Jung JU. 2003. Poly(ADP-ribose) polymerase 1 and Ste20-like kinase hKFC act as transcriptional repressors for $\gamma$-2 herpesvirus lytic replication. Mol Cell Biol 23: 82828294. doi:10.1128/MCB.23.22.8282-8294.2003
Ha HC, Juluri K, Zhou Y, Leung S, Hermankova M, Snyder SH. 2001. Poly(ADP-ribose) polymerase-1 is required for efficient HIV-1 integration. Proc Natl Acad Sci 98: 3364-3368. doi:10 $.1073 /$ pnas.051633498

Hans CP, Feng Y, Naura AS, Zerfaoui M, Rezk BM, Xia H, Kaye AD, Matrougui K, Lazartigues E, Boulares AH. 2009. Protective effects of PARP-1 knockout on dyslipidemia-induced autonomic and vascular dysfunction in ApoE mice: effects on eNOS and oxidative stress. PLoS One 4: e7430. doi:10.1371/ journal.pone.0007430

Hans CP, Feng Y, Naura AS, Troxclair D, Zerfaoui M, Siddiqui D, Jihang J, Kim H, Kaye AD, Matrougui K, et al. 2011. Opposing roles of PARP-1 in MMP-9 and TIMP-2 expression and mast cell degranulation in dyslipidemic dilated cardiomyopathy. Cardiovasc Pathol 20: e57-e68. doi:10.1016/j.carpath.2010 .03 .007

Haskó G, Mabley JG, Németh ZH, Pacher P, Deitch EA, Szabó C. 2002. Poly(ADP-ribose) polymerase is a regulator of chemokine production: relevance for the pathogenesis of shock and inflammation. Mol Med 8: 283-289. doi:10.1007/BF03402154

Hassa PO, Hottiger MO. 1999. A role of poly (ADP-ribose) polymerase in NF- $\mathrm{kB}$ transcriptional activation. Biol Chem 380: 953-959. doi:10.1515/BC.1999.118

Hassa PO, Haenni SS, Buerki C, Meier NI, Lane WS, Owen H, Gersbach M, Imhof R, Hottiger MO. 2005. Acetylation of poly(ADP-ribose) polymerase- 1 by $\mathrm{p} 300 / \mathrm{CREB}-$ binding protein regulates coactivation of NF- $\mathrm{kB}$-dependent transcription. J Biol Chem 280: 40450-40464. doi:10.1074/jbc.M507553200

Hayakawa S, Shiratori S, Yamato H, Kameyama T, Kitatsuji C, Kashigi F, Goto S, Kameoka S, Fujikura D, Yamada T, et al. 2011. ZAPS is a potent stimulator of signaling mediated by the RNA helicase RIG-I during antiviral responses. Nat Immunol 12: 37-44. doi:10.1038/ni.1963

Higashi H, Maejima T, Lee LH, Yamazaki Y, Hottiger MO, Singh SA, Aikawa M. 2019. A Study into the ADP-ribosylome of IFN- $\gamma$-stimulated THP-1 human macrophage-like cells identifies ARTD8/PARP14 and ARTD9/PARP9 ADP-ribosylation. I Proteome Res 18: 1607-1622. doi:10.1021/acs.jproteome $.8 \mathrm{~b} 00895$

Holbourn KP, Shone CC, Acharya KR. 2006. A family of killer toxins. Exploring the mechanism of ADP-ribosylating toxins. FEBS I 273: 4579-4593. doi:10.1111/j.1742-4658.2006.05442.x

Horwitz DA, Fahmy TM, Piccirillo CA, La Cava A. 2019. Rebalancing immune homeostasis to treat autoimmune diseases. Trends Immunol 40: 888-908. doi:10.1016/j.it.2019.08.003

Hottiger MO. 2015. Nuclear ADP-ribosylation and its role in chromatin plasticity, cell differentiation, and epigenetics. Annu Rev Biochem 84: 227-263. doi:10.1146/annurev-bio chem-060614-034506

Hottiger MO, Hassa PO, Luscher B, Schuler H, Koch-Nolte F. 2010. Toward a unified nomenclature for mammalian ADPribosyltransferases. Trends Biochem Sci 35: 208-219. doi:10 $.1016 /$ j.tibs.2009.12.003

Iansante V, Choy PM, Fung SW, Liu Y, Chai JG, Dyson J, Del Rio A, D'Santos C, Williams R, Chokshi S, et al. 2015. PARP14 promotes the Warburg effect in hepatocellular carcinoma by inhibiting JNK1-dependent PKM2 phosphorylation and activation. Nat Commun 6: 7882. doi:10.1038/ncomms8882

Iqbal MB, Johns M, Cao J, Liu Y, Yu SC, Hyde GD, Laffan MA, Marchese FP, Cho SH, Clark AR, et al. 2014. PARP-14 combines with tristetraprolin in the selective posttranscriptional control of macrophage tissue factor expression. Blood 124: 3646-3655. doi:10.1182/blood-2014-07-588046

Iwata H, Goettsch C, Sharma A, Ricchiuto P, Goh WW, Halu A, Yamada I, Yoshida H, Hara T, Wei M, et al. 2016. PARP9 
and PARP14 cross-regulate macrophage activation via STAT1 ADP-ribosylation. Nat Commun 7: 12849. doi:10.1038/ ncomms 12849

Jankevicius G, Hassler M, Golia B, Rybin V, Zacharias M, Timinszky G, Ladurner AG. 2013. A family of macrodomain proteins reverses cellular mono-ADP-ribosylation. Nat Struct Mol Biol 20: 508-514. doi:10.1038/nsmb.2523

Jiao S, Xia W, Yamaguchi H, Wei Y, Chen MK, Hsu JM, Hsu JL, Yu WH, Du Y, Lee HH, et al. 2017. PARP inhibitor upregulates PD-L1 expression and enhances cancer-associated immunosuppression. Clin Cancer Res 23: 3711-3720. doi:10.1158/ 1078-0432.CCR-16-3215

Johnston KW, Hosang MY, Andrews DF. 1987. Reproducibility of noninvasive vascular laboratory measurements of the peripheral circulation. J Vasc Surg 6: 147-151. doi:10.1067/mva.1987 .avs0060147

Juszczynski P, Kutok JL, Li C, Mitra J, Aguiar RC, Shipp MA. 2006. BAL1 and BBAP are regulated by a $\gamma$ interferon-responsive bidirectional promoter and are overexpressed in diffuse large B-cell lymphomas with a prominent inflammatory infiltrate. Mol Cell Biol 26: 5348-5359. doi:10.1128/MCB.0235105

Jwa M, Chang P. 2012. PARP16 is a tail-anchored endoplasmic reticulum protein required for the PERK- and IREla-mediated unfolded protein response. Nat Cell Biol 14: 1223-1230. doi:10.1038/ncb2593

Kameoka M, Tanaka Y, Ota K, Itaya A, Yoshihara K. 1999. Poly (ADP-ribose) polymerase is involved in PMA-induced activation of HIV-1 in U1 cells by modulating the LTR function. Biochem Biophys Res Commun 262: 285-289. doi:10.1006/bbrc .1999 .1146

Kameoka M, Nukuzuma S, Itaya A, Tanaka Y, Ota K, Ikuta K, Yoshihara K. 2004. RNA interference directed against Poly (ADP-Ribose) polymerase 1 efficiently suppresses human immunodeficiency virus type 1 replication in human cells. $I$ Virol 78: 8931-8934. doi:10.1128/JVI.78.16.8931-8934.2004

Kameoka M, Nukuzuma S, Itaya A, Tanaka Y, Ota K, Inada Y, Ikuta K, Yoshihara K. 2005. Poly(ADP-ribose)polymerase-1 is required for integration of the human immunodeficiency virus type 1 genome near centromeric alphoid DNA in human and murine cells. Biochem Biophys Res Commun 334: 412417. doi:10.1016/j.bbrc.2005.06.104

Kerns JA, Emerman M, Malik HS. 2008. Positive selection and increased antiviral activity associated with the PARP-containing isoform of human zinc-finger antiviral protein. PLOS Genet 4: e21. doi:10.1371/journal.pgen.0040021

Kleine H, Poreba E, Lesniewicz K, Hassa PO, Hottiger MO, Litchfield DW, Shilton BH, Lüscher B. 2008. Substrate-assisted catalysis by PARP10 limits its activity to mono-ADPribosylation. Mol Cell 32: 57-69. doi:10.1016/j.molcel.2008 .08 .009

Koonin EV, Gorbalenya AE, Purdy MA, Rozanov MN, Reyes GR, Bradley DW. 1992. Computer-assisted assignment of functional domains in the nonstructural polyprotein of hepatitis E virus: delineation of an additional group of positive-strand RNA plant and animal viruses. Proc Natl Acad Sci 89: 8259-8263. doi:10.1073/pnas.89.17.8259

Kozaki T, Takahama M, Misawa T, Matsuura Y, Akira S, Saitoh T. 2015. Role of zinc-finger anti-viral protein in host defense against Sindbis virus. Int Immunol 27: 357-364. doi:10 $.1093 /$ intimm/dxv010

Kozaki T, Komano J, Kanbayashi D, Takahama M, Misawa T, Satoh T, Takeuchi O, Kawai T, Shimizu S, Matsuura Y, et al. 2017. Mitochondrial damage elicits a TCDD-inducible poly(ADP-ribose) polymerase-mediated antiviral response.
Proc Natl Acad Sci 114: 2681-2686. doi:10.1073/pnas .1621508114

Krishnamurthy P, Kaplan MH. 2016. STAT6 and PARP family members in the development of $\mathrm{T}$ cell-dependent allergic inflammation. Immune Netw 16: 201-210. doi:10.4110/in .2016.16.4.201

Kunze FA, Hottiger MO. 2019. Regulating immunity via ADPribosylation: therapeutic implications and beyond. Trends Immunol 40: 159-173. doi:10.1016/j.it.2018.12.006

Larsen SC, Leutert M, Bilan V, Martello R, Jungmichel S, Young C, Hottiger MO, Nielsen ML. 2017. Proteome-wide identification of in vivo ADP-ribose acceptor sites by liquid chromatography-tandem mass spectrometry. Methods Mol Biol 1608: 149-162. doi:10.1007/978-1-4939-6993-7_11

Law LMJ, Razooky BS, Li MMH, You S, Jurado A, Rice CM, MacDonald MR. 2019. ZAP's stress granule localization is correlated with its antiviral activity and induced by virus replication. PLoS Pathog 15: e1007798. doi:10.1371/journal .ppat.1007798

Lee H, Komano J, Saitoh Y, Yamaoka S, Kozaki T, Misawa T, Takahama M, Satoh $\mathrm{T}$, Takeuchi $\mathrm{O}$, Yamamoto $\mathrm{N}$, et al. 2013. Zinc-finger antiviral protein mediates retinoic acid inducible gene I-like receptor-independent antiviral response to murine leukemia virus. Proc Natl Acad Sci 110: 1237912384. doi:10.1073/pnas. 1310604110

Leung AK. 2014. Poly(ADP-ribose): an organizer of cellular architecture. J Cell Biol 205: 613-619. doi:10.1083/jcb.201402114

Leung AK, Vyas S, Rood JE, Bhutkar A, Sharp PA, Chang P. 2011. Poly(ADP-ribose) regulates stress responses and microRNA activity in the cytoplasm. Mol Cell 42: 489-499. doi:10 $.1016 /$ j.molcel.2011.04.015

Leung AKL, McPherson RL, Griffin DE. 2018. Macrodomain ADP-ribosylhydrolase and the pathogenesis of infectious diseases. PLoS Pathog 14: e1006864. doi:10.1371/journal.ppat .1006864

Li Z, Yamauchi Y, Kamakura M, Murayama T, Goshima F, Kimura H, Nishiyama Y. 2012. Herpes simplex virus requires poly(ADP-ribose) polymerase activity for efficient replication and induces extracellular signal-related kinase-dependent phosphorylation and ICP0-dependent nuclear localization of tankyrase 1. J Virol 86: 492-503. doi:10.1128/JVI.05897-11

Li M, Yan K, Wei L, Yang J, Lu C, Xiong F, Zheng C, Xu W. 2015. Zinc finger antiviral protein inhibits coxsackievirus $\mathrm{B} 3$ virus replication and protects against viral myocarditis. Antiviral Res 123: 50-61. doi:10.1016/j.antiviral.2015.09.001

Li C, Debing Y, Jankevicius G, Neyts J, Ahel I, Coutard B, Canard B. 2016. Viral macro domains reverse protein ADP-ribosylation. I Virol 90: 8478-8486. doi:10.1128/JVI.00705-16

Li MM, Lau Z, Cheung P, Aguilar EG, Schneider WM, Bozzacco L, Molina H, Buehler E, Takaoka A, Rice CM, et al. 2017. TRIM25 enhances the antiviral action of zinc-finger antiviral protein (ZAP). PLoS Pathog 13: e1006145. doi:10.1371/journal .ppat.1006145

Li L, Zhao H, Liu P, Li C, Quanquin N, Ji X, Sun N, Du P, Qin CF, Lu N, et al. 2018. PARP12 suppresses Zika virus infection through PARP-dependent degradation of NS1 and NS3 viral proteins. Sci Signal 11: eaas9332. doi:10.1126/scisignal .aas9332

Li MMH, Aguilar EG, Michailidis E, Pabon J, Park P, Wu X, de Jong YP, Schneider WM, Molina H, Rice CM, et al. 2019. Characterization of novel splice variants of zinc finger antiviral protein (ZAP). I Virol 93: e00715-19. doi:10.1128/JVI .00715-19

Liu L, Ke Y, Jiang X, He F, Pan L, Xu L, Zeng X, Ba X. 2012a. Lipopolysaccharide activates ERK-PARP-1-RelA pathway and 
promotes nuclear factor- $\mathrm{\kappa} \mathrm{B}$ transcription in murine macrophages. Hum Immunol 73: 439-447. doi:10.1016/j.humimm .2012 .02 .002

Liu SY, Sanchez DJ, Aliyari R, Lu S, Cheng G. 2012b. Systematic identification of type I and type II interferon-induced antiviral factors. Proc Natl Acad Sci 109: 4239-4244. doi:10.1073/pnas .1114981109

Liu CH, Zhou L, Chen G, Krug RM. 2015a. Battle between influenza A virus and a newly identified antiviral activity of the PARP-containing ZAPL protein. Proc Natl Acad Sci 112: 14048-14053. doi:10.1073/pnas.1509745112

Liu L, Lear Z, Hughes DJ, Wu W, Zhou EM, Whitehouse A, Chen H, Hiscox JA. 2015b. Resolution of the cellular proteome of the nucleocapsid protein from a highly pathogenic isolate of porcine reproductive and respiratory syndrome virus identifies PARP-1 as a cellular target whose interaction is critical for virus biology. Vet Microbiol 176: 109-119. doi:10.1016/j .vetmic.2014.11.023

Mao R, Nie H, Cai D, Zhang J, Liu H, Yan R, Cuconati A, Block TM, Guo JT, Guo H. 2013. Inhibition of hepatitis B virus replication by the host zinc finger antiviral protein. PLoS Pathog 9: e1003494. doi:10.1371/journal.ppat.1003494

Martello R, Leutert M, Jungmichel S, Bilan V, Larsen SC, Young C, Hottiger MO, Nielsen ML. 2016. Proteome-wide identification of the endogenous ADP-ribosylome of mammalian cells and tissue. Nat Commun 7: 12917. doi:10.1038/ ncomms 12917

McCormick C, Khaperskyy DA. 2017. Translation inhibition and stress granules in the antiviral immune response. Nat Rev Immunol 17: 647-660. doi:10.1038/nri.2017.63

McPherson RL, Abraham R, Sreekumar E, Ong SE, Cheng SJ, Baxter VK, Kistemaker HA, Filippov DV, Griffin DE, Leung AK. 2017. ADP-ribosylhydrolase activity of Chikungunya virus macrodomain is critical for virus replication and virulence. Proc Natl Acad Sci 114: 1666-1671. doi:10.1073/pnas .1621485114

Mehrotra P, Riley JP, Patel R, Li F, Voss L, Goenka S. 2011. PARP14 functions as a transcriptional switch for Stat6-dependent gene activation. J Biol Chem 286: 1767-1776. doi:10.1074/ jbc.M110.157768

Mehrotra P, Hollenbeck A, Riley JP, Li F, Patel RJ, Akhtar N, Goenka S. 2013. Poly (ADP-ribose) polymerase 14 and its enzyme activity regulates $\mathrm{T}(\mathrm{H}) 2$ differentiation and allergic airway disease. I Allergy Clin Immunol 131: 521-531.e12. doi:10.1016/j.jaci.2012.06.015

Mehrotra P, Krishnamurthy P, Sun J, Goenka S, Kaplan MH. 2015. Poly-ADP-ribosyl polymerase-14 promotes T helper 17 and follicular $\mathrm{T}$ helper development. Immunology 146: 537546. doi:10.1111/imm.12515

Minhas PS, Liu L, Moon PK, Joshi AU, Dove C, Mhatre S, Contrepois K, Wang Q, Lee BA, Coronado M, et al. 2019. Macrophage de novo $\mathrm{NAD}^{+}$synthesis specifies immune function in aging and inflammation. Nat Immunol 20: 50-63. doi:10.1038/ s41590-018-0255-3

Minotti R, Andersson A, Hottiger MO. 2015. ARTD1 suppresses interleukin 6 expression by repressing MLL1-dependent histone H3 trimethylation. Mol Cell Biol 35: 3189-3199.

Miwa M, Sugimura T. 1971. Splitting of the ribose-ribose linkage of poly(adenosine diphosphate-robose) by a calf thymus extract. J Biol Chem 246: 6362-6364.

Mukhopadhyay P, Horvath B, Rajesh M, Varga ZV, Gariani K, Ryu D, Cao Z, Holovac E, Park O, Zhou Z, et al. 2017. PARP inhibition protects against alcoholic and non-alcoholic steatohepatitis. I Hepatol 66: 589-600. doi:10.1016/j.jhep .2016 .10 .023
Muller S, Moller P, Bick MJ, Wurr S, Becker S, Gunther S, Kummerer BM. 2007. Inhibition of filovirus replication by the zinc finger antiviral protein. I Virol 81: 2391-2400. doi:10 $.1128 /$ JVI.01601-06

Murray PJ, Wynn TA. 2011. Protective and pathogenic functions of macrophage subsets. Nat Rev Immunol 11: 723-737. doi:10 $.1038 /$ nri3073

Murray PJ, Allen JE, Biswas SK, Fisher EA, Gilroy DW, Goerdt S, Gordon S, Hamilton JA, Ivashkiv LB, Lawrence T, et al. 2014. Macrophage activation and polarization: nomenclature and experimental guidelines. Immunity 41: 14-20. doi:10.1016/j .immuni.2014.06.008

Nahrendorf M, Swirski FK. 2016. Abandoning M1/M2 for a network model of macrophage function. Circ Res 119: 414-417. doi:10.1161/CIRCRESAHA.116.309194

Nakano T, Fukuda D, Koga J, Aikawa M. 2016. Delta-like ligand 4-notch signaling in macrophage activation. Arterioscler Thromb Vasc Biol 36: 2038-2047. doi:10.1161/ATVBAHA .116 .306926

Nasta F, Laudisi F, Sambucci M, Rosado MM, Pioli C. 2010. Increased Foxp $3^{+}$regulatory T cells in poly(ADP-Ribose) polymerase-1 deficiency. I Immunol 184: 3470-3477. doi:10 $.4049 /$ jimmunol.0901568

Navarro J, Gozalbo-López B, Méndez AC, Dantzer F, Schreiber V, Martínez C, Arana DM, Farrés J, Revilla-Nuin B, Bueno MF, et al. 2017. PARP-1/PARP-2 double deficiency in mouse $\mathrm{T}$ cells results in faulty immune responses and $\mathrm{T}$ lymphomas. Sci Rep 7: 41962. doi:10.1038/srep41962

Noh CW, Cho HJ, Kang HR, Jin HY, Lee S, Deng H, Wu TT, Arumugaswami V, Sun R, Song MJ. 2012. The virion-associated open reading frame 49 of murine $\gamma$ herpesvirus 68 promotes viral replication both in vitro and in vivo as a derepressor of RTA. J Virol 86: 1109-1118. doi:10.1128/JVI.05785-11

Nukuzuma S, Kameoka M, Sugiura S, Nakamichi K, Nukuzuma C, Takegami T. 2013. Suppressive effect of PARP-1 inhibitor on JC virus replication in vitro. I Med Virol 85: 132-137. doi:10.1002/jmv.23443

Oka S, Kato J, Moss J. 2006. Identification and characterization of a mammalian 39-kDa poly(ADP-ribose) glycohydrolase. I Biol Chem 281: 705-713. doi:10.1074/jbc.M510290200

Oliver FJ, Ménissier-de Murcia J, Nacci C, Decker P, Andriantsitohaina R, Muller S, de la Rubia G, Stoclet JC, de Murcia G. 1999. Resistance to endotoxic shock as a consequence of defective NF- $\mathrm{kB}$ activation in poly (ADP-ribose) polymerase-1 deficient mice. EMBO I 18: 4446-4454. doi:10.1093/emboj/ 18.16.4446

O'Rourke SA, Dunne A, Monaghan MG. 2019. The role of macrophages in the infarcted myocardium: orchestrators of ECM remodeling. Front Cardiovasc Med 6: 101. doi:10.3389/fcvm .2019 .00101

Othman N, Jamal R, Abu N. 2019. Cancer-derived exosomes as effectors of key inflammation-related players. Front Immunol 10: 2103. doi:10.3389/fimmu.2019.02103

Oumouna-Benachour K, Hans CP, Suzuki Y, Naura A, Datta R, Belmadani S, Fallon K, Woods C, Boulares AH. 2007. Poly (ADP-ribose) polymerase inhibition reduces atherosclerotic plaque size and promotes factors of plaque stability in apolipoprotein E-deficient mice: effects on macrophage recruitment, nuclear factor- $\mathrm{kB}$ nuclear translocation, and foam cell death. Circulation 115: 2442-2450. doi:10.1161/CIRCULATIO NAHA.106.668756

Parent M, Yung TM, Rancourt A, Ho EL, Vispé S, SuzukiMatsuda F, Uehara A, Wada T, Handa H, Satoh MS. 2005. Poly(ADP-ribose) polymerase-1 is a negative regulator of HIV-1 transcription through competitive binding to TAR 
RNA with Tat.positive transcription elongation factor $b$ (p-TEFb) complex. I Biol Chem 280: 448-457. doi:10.1074/ jbc.M408435200

Park E, Griffin DE. 2009. The nsP3 macro domain is important for Sindbis virus replication in neurons and neurovirulence in mice. Virology 388: 305-314. doi:10.1016/j.virol.2009.03.031

Park H, Ishihara D, Cox D. 2011. Regulation of tyrosine phosphorylation in macrophage phagocytosis and chemotaxis. Arch Biochem Biophys 510: 101-111. doi:10.1016/j.abb.2011.02 .019

Qin W, Wu HJ, Cao LQ, Li HJ, He CX, Zhao D, Xing L, Li PQ, Jin X, Cao HL. 2019. Research progress on PARP14 as a drug target. Front Pharmacol 10: 172. doi:10.3389/fphar.2019.00172

Rack JG, Perina D, Ahel I. 2016. Macrodomains: structure, function, evolution, and catalytic activities. Annu Rev Biochem 85: 431-454. doi:10.1146/annurev-biochem-060815-014935

Ricchiuto P, Iwata H, Yabusaki K, Yamada I, Pieper B, Sharma A, Aikawa M, Singh SA. 2015. mIMT-visHTS: a novel method for multiplexing isobaric mass tagged datasets with an accompanying visualization high throughput screening tool for protein profiling. J Proteomics 128: 132-140. doi:10.1016/j.jprot.2015 .07 .024

Riley JP, Kulkarni A, Mehrotra P, Koh B, Perumal NB, Kaplan $\mathrm{MH}$, Goenka S. 2013. PARP-14 binds specific DNA sequences to promote Th2 cell gene expression. PLoS One 8: e83127. doi:10.1371/journal.pone.0083127

Rosado MM, Bennici E, Novelli F, Pioli C. 2013. Beyond DNA repair, the immunological role of PARP-1 and its siblings. Immunology 139: 428-437. doi:10.1111/imm.12099

Rosenthal F, Feijs KL, Frugier E, Bonalli M, Forst AH, Imhof R, Winkler HC, Fischer D, Caflisch A, Hassa PO, et al. 2013. Macrodomain-containing proteins are new mono-ADP-ribosylhydrolases. Nat Struct Mol Biol 20: 502-507. doi:10.1038/ nsmb. 2521

Ryu KW, Kim DS, Kraus WL. 2015. New facets in the regulation of gene expression by ADP-ribosylation and poly(ADP-ribose) polymerases. Chem Rev 115: 2453-2481. doi:10.1021/ cr5004248

Saenz L, Lozano JJ, Valdor R, Baroja-Mazo A, Ramirez P, Parrilla P, Aparicio P, Sumoy L, Yélamos J. 2008. Transcriptional regulation by poly(ADP-ribose) polymerase-1 during T cell activation. BMC Genomics 9: 171. doi:10.1186/1471-2164-9-171

Schwerk J, Soveg FW, Ryan AP, Thomas KR, Hatfield LD, Ozarkar S, Forero A, Kell AM, Roby JA, So L, et al. 2019. RNA-binding protein isoforms ZAP-S and ZAP-L have distinct antiviral and immune resolution functions. Nat Immunol 20: 16101620. doi:10.1038/s41590-019-0527-6

Shrestha E, Hussein MA, Savas JN, Ouimet M, Barrett TJ, Leone S, Yates JR 3rd, Moore KJ, Fisher EA, Garabedian MJ. 2016. Poly(ADP-ribose) polymerase 1 represses liver $\mathrm{X}$ receptor-mediated ABCA1 expression and cholesterol efflux in macrophages. I Biol Chem 291: 11172-11184. doi:10.1074/jbc .M116.726729

Su C, Zhang J, Zheng C. 2015. Herpes simplex virus 1 UL41 protein abrogates the antiviral activity of hZAP by degrading its mRNA. Virol J 12: 203. doi:10.1186/s12985-015-0433-y

Swirski FK, Nahrendorf M. 2018. Cardioimmunology: the immune system in cardiac homeostasis and disease. Nat Rev Immunol 18: 733-744. doi:10.1038/s41577-018-0065-8

Tabas I, Lichtman AH. 2017. Monocyte-macrophages and T cells in atherosclerosis. Immunity 47: 621-634. doi:10.1016/j .immuni.2017.09.008

Takata MA, Gonçalves-Carneiro D, Zang TM, Soll SJ, York A, Blanco-Melo D, Bieniasz PD. 2017. CG dinucleotide suppres- sion enables antiviral defence targeting non-self RNA. Nature 550: 124-127. doi:10.1038/nature24039

Tang Q, Wang X, Gao G. 2017. The short form of the zinc finger antiviral protein inhibits influenza A virus protein expression and is antagonized by the virus-encoded NS1. I Virol 91: e01909-16.

Tempera I, Deng Z, Atanasiu C, Chen CJ, D'Erme M, Lieberman PM. 2010. Regulation of Epstein-Barr virus OriP replication by poly(ADP-ribose) polymerase 1. J Virol 84: 4988-4997. doi:10 $.1128 /$ JVI.02333-09

Tietzel I, Mosser DM. 2002. The modulation of macrophage activation by tyrosine phosphorylation. Front Biosci 7: d1494d1502. doi:10.2741/tietzel

Trott DW, Fadel PJ. 2019. Inflammation as a mediator of arterial ageing. Exp Physiol 104: 1455-1471. doi:10.1113/EP087499

Ullrich O, Diestel A, Eyüpoglu IY, Nitsch R. 2001. Regulation of microglial expression of integrins by poly(ADP-ribose) polymerase-1. Nat Cell Biol 3: 1035-1042. doi:10.1038/ncb12011035

Vergadi E, Ieronymaki E, Lyroni K, Vaporidi K, Tsatsanis C. 2017. Akt signaling pathway in macrophage activation and M1/M2 polarization. J Immunol 198: 1006-1014. doi:10.4049/jimmu nol.1601515

Verheugd P, Forst AH, Milke L, Herzog N, Feijs KL, Kremmer E, Kleine H, Luscher B. 2013. Regulation of NF- $\mathrm{kB}$ signalling by the mono-ADP-ribosyltransferase ARTD10. Nat Commun 4: 1683. doi: $10.1038 /$ ncomms 2672

von Lukowicz T, Hassa PO, Lohmann C, Borén J, Braunersreuther V, Mach F, Odermatt B, Gersbach M, Camici GG, Stähli BE, et al. 2008. PARP1 is required for adhesion molecule expression in atherogenesis. Cardiovasc Res 78: 158-166. doi:10 $.1093 / \mathrm{cvr} / \mathrm{cvm} 110$

Vyas S, Chesarone-Cataldo M, Todorova T, Huang YH, Chang P. 2013. A systematic analysis of the PARP protein family identifies new functions critical for cell physiology. Nat Commun 4: 2240 . doi: $10.1038 /$ ncomms 3240

Wahlberg E, Karlberg T, Kouznetsova E, Markova N, Macchiarulo A, Thorsell AG, Pol E, Frostell A, Ekblad T, Oncu D, et al. 2012. Family-wide chemical profiling and structural analysis of PARP and tankyrase inhibitors. Nat Biotechnol 30: 283288. doi:10.1038/nbt.2121

Wang X, Tu F, Zhu Y, Gao G. 2012. Zinc-finger antiviral protein inhibits XMRV infection. PLoS One 7: e39159. doi:10.1371/ journal.pone.0039159

Wang G, Huang X, Li Y, Guo K, Ning P, Zhang Y. 2013. PARP-1 inhibitor, DPQ, attenuates LPS-induced acute lung injury through inhibiting NF-kB-mediated inflammatory response. PLoS One 8: e79757. doi:10.1371/journal.pone.0079757

Wang X, Li MM, Zhao J, Li S, MacDonald MR, Rice CM, Gao X, Gao G. 2016. Sindbis virus can exploit a host antiviral protein to evade immune surveillance. J Virol 90: 10247-10258. doi:10 $.1128 /$ JVI.01487-16

Welsby I, Hutin D, Gueydan C, Kruys V, Rongvaux A, Leo O. 2014. PARP12, an interferon-stimulated gene involved in the control of protein translation and inflammation. I Biol Chem 289: 26642-26657. doi:10.1074/jbc.M114.589515

Wynn TA, Vannella KM. 2016. Macrophages in tissue repair, regeneration, and fibrosis. Immunity 44: 450-462. doi:10 .1016/j.immuni.2016.02.015

Xie L, Lu B, Zheng Z, Miao Y, Liu Y, Zhang Y, Zheng C, Ke X, Hu $\mathrm{Q}$, Wang H. 2018. The $3 \mathrm{C}$ protease of enterovirus A71 counteracts the activity of host zinc-finger antiviral protein (ZAP). J Gen Virol 99: 73-85. doi:10.1099/jgv.0.000982

Xuan Y, Liu L, Shen S, Deng H, Gao G. 2012. Zinc finger antiviral protein inhibits murine $\gamma$ herpesvirus $68 \mathrm{M} 2$ expression and 
regulates viral latency in cultured cells. I Virol 86: 1243112434. doi:10.1128/JVI.01514-12

Xuan Y, Gong D, Qi J, Han C, Deng H, Gao G. 2013. ZAP inhibits murine $\gamma$ herpesvirus 68 ORF64 expression and is antagonized by RTA. J Virol 87: 2735-2743. doi:10.1128/JVI.03015-12

Yamada T, Horimoto H, Kameyama T, Hayakawa S, Yamato H, Dazai M, Takada A, Kida H, Bott D, Zhou AC, et al. 2016. Constitutive aryl hydrocarbon receptor signaling constrains type I interferon-mediated antiviral innate defense. Nat Immunol 17: 687-694. doi:10.1038/ni.3422

Yang Z, Li L, Chen L, Yuan W, Dong L, Zhang Y, Wu H, Wang C. 2014. PARP-1 mediates LPS-induced HMGB1 release by macrophages through regulation of HMGB1 acetylation. I Immunol 193: 6114-6123. doi:10.4049/jimmunol.1400359

Yang CS, Jividen K, Spencer A, Dworak N, Ni L, Oostdyk LT, Chatterjee M, Kuśmider B, Reon B, Parlak M, et al. 2017. Ubiquitin modification by the E3 ligase/ADP-ribosyltransferase Dtx3L/Parp9. Mol Cell 66: 503-516.e5. doi:10.1016/j.molcel .2017 .04 .028

Zhang P, Nakatsukasa H, Tu E, Kasagi S, Cui K, Ishikawa M, Konkel JE, Maruyama T, Wei G, Abbatiello B, et al. 2013. PARP-1 regulates expression of TGF- $\beta$ receptors in T cells. Blood 122: 2224-2232. doi:10.1182/blood-2013-05-503250
Zhang Y, Mao D, Roswit WT, Jin X, Patel AC, Patel DA, Agapov E, Wang Z, Tidwell RM, Atkinson JJ, et al. 2015. PARP9DTX3L ubiquitin ligase targets host histone H2BJ and viral $3 \mathrm{C}$ protease to enhance interferon signaling and control viral infection. Nat Immunol 16: 1215-1227. doi:10.1038/ni.3279

Zhao Y, Song Z, Bai J, Liu X, Nauwynck H, Jiang P. 2019. ZAP, a $\mathrm{CCCH}$-type zinc finger protein, inhibits porcine reproductive and respiratory syndrome virus replication and interacts with viral Nsp9. J Virol 93: e00001-19. doi:10.1128/JVI.00001-19

Zheng X, Wang X, Tu F, Wang Q, Fan Z, Gao G. 2017. TRIM25 is required for the antiviral activity of zinc finger antiviral protein. J Virol 91: e00088-17. doi:10.1128/JVI.00088-17

Zhou D, Huang C, Lin Z, Zhan S, Kong L, Fang C, Li J. 2014. Macrophage polarization and function with emphasis on the evolving roles of coordinated regulation of cellular signaling pathways. Cell Signal 26: 192-197. doi:10.1016/j.cellsig.2013 .11 .004

Zhu Y, Chen G, Lv F, Wang X, Ji X, Xu Y, Sun J, Wu L, Zheng YT, Gao G. 2011. Zinc-finger antiviral protein inhibits HIV-1 infection by selectively targeting multiply spliced viral mRNAs for degradation. Proc Natl Acad Sci 108: 15834-15839. doi:10 $.1073 /$ pnas.1101676108 


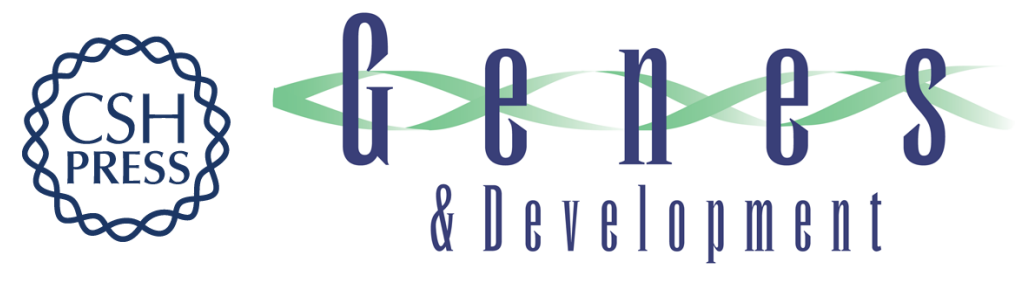

\title{
The impact of PARPs and ADP-ribosylation on inflammation and host- pathogen interactions
}

\author{
Anthony R. Fehr, Sasha A. Singh, Catherine M. Kerr, et al. \\ Genes Dev. 2020, 34: originally published online February 6, 2020 \\ Access the most recent version at doi:10.1101/gad.334425.119
}

\section{Related Content Interplay between compartmentalized NAD+ synthesis and consumption: a focus on the PARP family \\ Michael S. Cohen \\ Genes Dev. March , 2020 34: 254-262 Nuclear PARPs and genome integrity \\ Kameron Azarm and Susan Smith \\ Genes Dev. March , 2020 34: 285-301 The role of ADP-ribose metabolism in metabolic regulation, adipose tissue differentiation, and metabolism \\ Magdolna Szántó and Peter Bai \\ Genes Dev. March , 2020 34: 321-340 PARPs and ADP-ribosylation: 60 years on \\ W. Lee Kraus \\ Genes Dev. March , 2020 34: 251-253 PARP and PARG inhibitors in cancer treatment Dea Slade \\ Genes Dev. March , 2020 34: 360-394 PARPs and ADP-ribosylation in RNA biology: from RNA expression and processing to protein translation and proteostasis Dae-Seok Kim, Sridevi Challa, Aarin Jones, et al. \\ Genes Dev. March , 2020 34: 302-320 (ADP-ribosyl)hydrolases: structure, function, and biology \\ Johannes Gregor Matthias Rack, Luca Palazzo and Ivan Ahel \\ Genes Dev. March , 2020 34: 263-284}

References This article cites 179 articles, 75 of which can be accessed free at:

http://genesdev.cshlp.org/content/34/5-6/341.full.html\#ref-list-1

Articles cited in:

http://genesdev.cshlp.org/content/34/5-6/341.full.html\#related-urls

Creative This article, published in Genes \& Development, is available under a Creative Commons

Commons

License (Attribution 4.0 International), as described at

License http://creativecommons.org/licenses/by/4.0/.

Email Alerting

Receive free email alerts when new articles cite this article - sign up in the box at the top

Service right corner of the article or click here.

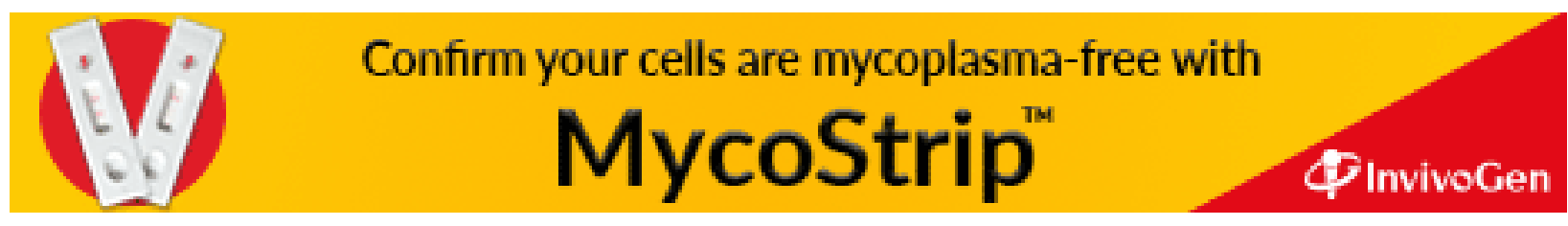

